Sonderdruck aus

Matthias Becher / Alheydis Plassmann (Hg.)

\title{
Streit am Hof im frühen Mittelalter
}

Mit 12 Abbildungen

V\&R unipress

Bonn University Press

ISBN 978-3-89971-884-3

ISBN 978-3-86234-884-8 (E-Book) 



\section{Inhalt}

Danksagung ........................... 7

Matthias Becher

Gedanken zur Einführung . . . . . . . . . . . . . . 9

Daniel G. König

Öffentliche religiöse Auseinandersetzungen unter Beteiligung

spätantik-frühmittelalterlicher Höfe - Versuch einer Typologie . . . . . . 17

Roland Steinacher

Der vandalische Königshof als Ort der öffentlichen religiösen

Auseinandersetzung .................... 45

Alheydis Plassmann

Interessenvertretung und Intrigen am ostgotischen Königshof $\quad \ldots .75$

Caspar Ehlers

Sachsen als sächsische Bischöfe. Die Kirchenpolitik der karolingischen und ottonischen Könige in einem neuen Licht . . . . . . . . . . . . 95

Daniel Eichler

Karolingische Höfe und Versammlungen - Grundvoraussetzungen . . . . 121

Jennifer R. Davis

Charlemagne's Settlement of Disputes . . . . . . . . . . . . . . 149

Eric J. Goldberg

Dominus Hludowicus serenissimus imperator sedens pro tribunali:

Conflict, Justice, and Ideology at the Court of Louis the German . . . . . 175 
Matthias Schrör

Aufstieg und Fall des Erzbischofs Ebo von Reims . . . . . . . . . . 203

Andrea Stieldorf

Adel an der Peripherie im Streit mit dem höfischen Zentrum . . . . . . . 223

Thomas Scharff

Streitschlichtung am Hof. Versöhnungsrituale, Eide und Historiographie im 9. Jahrhundert . . . . . . . . . . . . . . . . . . . 247

Martina Giese

Kompetitive Aspekte höfischer Jagdaktivitäten im Frühmittelalter . . . . 263

Linda Dohmen

...evertit palatium, destruxit consilium... - Konflikte im und um den Rat des Herrschers am Beispiel der Auseinandersetzungen am Hof Ludwigs des Frommen $(830 / 31)$. . . . . . . . . . . . . . . 285

Charles West

Evaluating conflict at court: a West Frankish perspective . . . . . . . . 317

Manfred Luchterhandt

Bilder ohne Worte. Protokoll und höfischer Luxus in den

Empfangszeremonien des mittelbyzantinischen Kaiserhofs . . . . . . . 331

Florian Hartmann

Streit an der cathedra Petri oder Streit um die cathedra Petri? Konflikte um den Papstthron in der Deutung päpstlicher Quellen . . . . . . . . . 365

Jochen Johrendt

Eine Leiche vor Gericht. Streit vor und um Päpste in der zweiten Hälfte des 9. Jahrhunderts . . . . . . . . . . . . . . . . . . . . . . 389

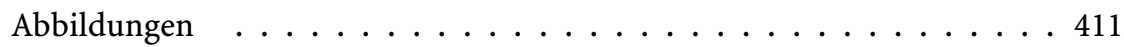

Beiträgerverzeichnis . . . . . . . . . . . . . . . 417

Personenregister ... . . . . . . . . . . . . . 419

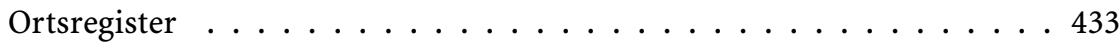




\section{Der vandalische Königshof als Ort der öffentlichen religiösen Auseinandersetzung*}

Das römische Nordafrika erlebte, wie das gesamte westliche und östliche Imperium, zwischen dem 5. und dem 7. Jahrhundert einschneidende politische, ökonomische und gesellschaftliche Veränderungen. Über deren Beschreibung oder gar Erklärung ist sich die Forschung nicht einig. Italien, Gallien, Spanien und Afrika transformierten zu den Regna der Ostgoten wie Langobarden, Burgunder wie Franken, Westgoten und Vandalen wie Alanen. Aus römischen Provinzen entwickelten sich im Laufe von Jahrhunderten mittelalterliche europäische Länder und Nationen, das römische Afrika allerdings wurde nicht zu einem Vandalusien, sondern zum arabischsprachigen Tunesien. In Konstantinopel regierte im 5. Jh. weiter der sich selbst als der einzig legitime Herrscher definierende basileus. ${ }^{1}$

Das aus den Provinzen Africa Proconsularis und Africa Byzacena wie Inseln des westlichen Mittelmeers entstandene vandalische Machtgebiet war das erste politische Konstrukt der Spätantike, in dem eine Kriegerelite barbarischer Herkunft auf Basis der Strukturen römischer Provinzen für ein Jahrhundert regieren konnte. Ein rex Vandalorum et Alanorum verwaltete diese römischen

\footnotetext{
* Verschriftliche Fassung des Vortrags „Der vandalische Königshof als Ort der öffentlichen religiösen Auseinandersetzung “ auf der Tagung „Streit am Hof im frühen Mittelalter" in Bonn 23. September 2009. Ich danke Prof. Matthias Becher für die Einladung zur Tagung. Guido M. Berndt (Erlangen), Philipp von Rummel (Rom) und Konrad Vössing (Bonn) danke ich für Anregungen, Hilfe und Kritik. Die Erstellung der Aufsatzfassung wurde durch ein Forschungsstipendium der GERDA HENKEL STIFTUNG ermöglicht. In diesem Rahmen bereitet der Autor eine deutschsprachige Monographie zur Geschichte der Vandalen mit dem Arbeitstitel „Die Vandalen. Ein spätrömisches Königreich in Nordafrika“ vor.

1 Walter PoHL, Rome and the Barbarians in the fifth century, in: Antiquité Tardive 16 (2008) S. 93 -101; Walter PoHL, Introduction: The Empire and the integration of barbarians, in: Kingdoms of the Empire. The Integration of Barbarians in Late Antiquity, hg. von Walter PoHL (The Transformation of the Roman World 1) Leiden - Boston - Köln 1997, S. 1-12; Walter PoHL, Justinian and the barbarian kingdoms, in: The Cambridge Companion to the Age of Justinian, hg. von Michael MaAs, Cambridge 2005, S. 448-476; Walter A. Goffart, Barbarian Tides. The Migration Age and the Later Roman Empire (The Middle Ages series) Philadelphia 2006.
} 
Provinzen, die im Verständnis der vandalischen Könige a Deo nobis concessae waren. Gerade dass Nordafrika keine weitere Entwicklung zu einem lateinischen, europäischen Land nach dem 6. Jahrhundert erlebte, macht es zu einem interessanten Studienobjekt für das Verständnis der Strukturen der Spätantike und des frühen Mittelalters. ${ }^{2}$

Die zwischen Rom, Trier, Mailand, Ravenna und anderen Städten wechselnde kaiserliche Hofhaltung des Westreichs endet strukturell nicht mit der Absetzung des Romulus im Jahre 476. Unter Odoaker und den ostgotischen Königen, als erstem dem patricius Theoderich, bestand etwa in Ravenna eine höfische Struktur. Die barbarischen Regna des Westens verfügten in praktisch allen Fällen, wenn auch in verkleinertem Maß, über einen Hof, der dem kaiserlichen in den Grundzügen der Organisation entsprach. ${ }^{3}$

Der spätantike Kaiserhof, der sacer comitatus, berief sich auf eine religiöse Legitimierung. Führungskompetenzen und Leitungsaufgaben, also staatliche Hoheitsrechte, wurden auf genau definierte Personengruppen im sacer comitatus übertragen, die im kaiserlichen Palast agierten. Der karthagische Hof der vandalischen Könige wird nun in den Quellen als domus regia, aula oder $p a-$ latium bezeichnet. Aus der bereits erwähnten Formulierung a Deo nobis concessae im ersten bei Victor von Vita überlieferten Mandat König Hunerichs, in dem von Gott gegebenen Herrschaftsansprüchen die Rede ist, lässt sich zumindest ansatzweise eine der kaiserlichen vergleichbare Legitimierung vandalischer Königsherrschaft ableiten. ${ }^{4}$ Von Anfang an erscheint der Hof der hasdingischen Könige der Vandalen und Alanen in Karthago in imperialem Glanz. Übernommen wurde mit großer Wahrscheinlichkeit der Palast des Prokonsuls

2 Roland Steinacher, Gruppen und Identitäten. Gedanken zur Bezeichnung, vandalisch', in: Das Reich der Vandalen und seine (Vor-)Geschichten, hg. von Guido M. BERNDT - Roland Steinacher (Österr. Akademie der Wissenschaften, Denkschriften der phil.-hist. Klasse 366, Forschungen zur Geschichte des Mittelalters 13) Wien 2008, S. 243-260; Andrew H. MerRILls - Richard Miles, The Vandal,( The Peoples of Europe) Oxford 2010; Guido M. BerndT, Konflikt und Anpassung. Studien zu Migration und Ethnogenese der Vandalen (Historische Studien 489) Husum 2007, S. 175-274.

3 Alexander Demandt, Die Spätantike. Römische Geschichte von Diocletian bis Justinian 284 565 n. Chr. (Handbuch der Altertumswissenschaft, Abt. 3-6) München 2007, S. 291; Peter Classen, Spätrömische Grundlagen mittelalterlicher Kanzleien, in: Ausgewählte Aufsätze von Peter Classen, hg. von Josef Fleckenstein (Konstanzer Arbeitskreis für Mittelalterliche Geschichte. Vorträge und Forschungen 28) Sigmaringen 1983, S. 67-84.

4 Victor Vitensis, Historia persecutionis Africanae provinciae sub Geiserico et Hunirico regibus Wandalorum 1,$22 ; 1,43 ; 2,8 ; 2,10 ; 2,23 ; 2,39 ; 3,11$ und 13, ed. Serge LANCEL (Collection des Universités de France, Série latine 368) Paris 2002; vgl. Gideon MAIER, Amtsträger und Herrscher in der Romania Gothica. Vergleichende Untersuchungen zu den Institutionen der ostgermanischen Völkerwanderungsreiche (Historia Einzelschriften 181) Stuttgart 2005, S. 121-206, besonders S. 123 und Anm. 10, S. 196 f., 129 f., 143 f., 163, 196 ff.; Dirk SCHLINKERT, Vom Haus zum Hof. Aspekte höfischer Herrschaft in der Spätantike, in: Klio 78/ 2 (1996) S. $454-482$. 
am Byrsahügel Karthagos und der Hof blieb dort bis zur Eroberung der afrikanischen Provinzen durch die Truppen Kaiser Justinians. Belisar setzte dann auch 534 in diesem Gebäude eine provisorische byzantinische Verwaltung ein. ${ }^{5}$

Prokop berichtet, Gelimer bewirte die Großen unter den Nordafrikanern in diesem palatium. Als Belisar nach seinem Sieg den Palast betritt, findet er jene Speisen vor, die für vornehme Vandalen der unmittelbaren Umgebung Gelimers gedacht waren, sogar die Dienerschaft des Vandalenkönigs ist noch vor Ort. Prokop bringt in dieser Passage eine unmittelbare Analogie zum römischen Kaiserpalast: Der byzantinische Offizier führt aus, der vandalische Speiseraum werde nach dem dort verwendeten Dreifuß Delphix genannt, gerade wie das auch in den Kaiserpalästen üblich sei als Bezeichnung des kaiserlichen Speisesaals. Seit Augustus heiße der Kaiserpalast palatium und so auch der vandalische. ${ }^{6}$

Neben dem königlichen Hof in Karthago unterhielten Angehörige des hasdingischen Hauses eigene, kleinere Höfe. Die Könige selbst scheinen Sommerpaläste außerhalb der Stadt besessen zu haben. Für Geiserich, Thrasamund, Hilderich und Gelimer finden sich solche Anwesen erwähnt. ${ }^{7}$

Im Gegensatz zum fränkischen oder westgotischen Königtum hatte der vandalische Hof also fixe Residenzen, ohne dabei jedoch auf Karthago beschränkt zu bleiben. Gleichzeitig stellten die kleineren Hofhaltungen der Mitglieder der Königssippe eigene Machtzentren dar. Die innervandalischen Putschversuche der Jahre 442, 481 und 531 nahmen von solchen ,Nebenhöfen“ ihren Ausgang. Für diese Höfe ist ein kleineres, aber ähnlich hierarchisiertes Personal in den Quellen genannt wie für den Königshof in Karthago. Geiserich soll verfügt haben, dass an seinem und an den Höfen seiner Söhne nur Arianer tätig sein dürfen (... intra aulam suam filiorumque suorum nonnisi Arriani per diversa ministeria ponerentur). ${ }^{8}$ Soweit die wenigen Informationen, die sich bezüglich des Hofes an sich aus den Quellen gewinnen lassen.

5 Zum Byrsahügel vgl. Anna Leone, Changing Townscapes in North Africa from Late Antiquity to the Arab Conquest, Bari 2007, S. 159; Aïcha Ben Abed Ben Khader - Noël Duval, Carthage. La capitale du royaume vandale et les villes de Tunisie à l'époque vandale, in: Sedes regiae. ann. 400 - 800, hg. von Gisela Ripoll - Josep M. GuRT, Barcelona 2000, S. 163-218, hier S. 189; Christian Courtors, Les Vandales et l'Afrique, Paris 1955, S. 250.

6 Prokop, Bella, 3, 21 1, ed. Otto VEH, lat. und deut. (Sammlung Tusculum) München 1971.

7 Vict. Vit. (wie Anm. 4) 1, 17: Geiserich für Maxula; Thrasamund für Alianae, Hilderich für Anclas: Anthologia Latina. Carmina in codicibus scripta 201-205, $210-214,376$, ed. David R. SHACKLETON BAILEY (Bibliotheca scriptorvm Graecorvm et Romanorvm Tevbneriana) Stuttgart 1982; Gelimer für Hermiana und der möglicherweise königliche Palast in Grasse: Procopius, Bella 3, 14, 10; 3, 17, 18. Vgl. dazu dazu Guido M. BERNDT, Architecture and the Vandal Elite in Africa, in: Hortus Artium Medievalium 13/2 (2007) S. 291-300.

8 Vict. Vit. (wie Anm. 4) 1, 43; Prosper Tiro, Epitoma chronicon 1348, ed. Theodor Mommsen (MGH AA 9, CM 1) Berlin 1892, S. 341 -499, hier S. 487: In Gisiricum de successu rerum etiam apud suos superbientem quidam optimates ipsius conspiraverunt. Sed molitione detecta multis 
442 führte die Opposition von Angehörigen des hasdingischen Hauses und anderer Großer gegen Geiserich zur Ermordung der Frau und der Kinder seines Bruders Gunderich, die Geiserich im Fluss Ampsaga (Oued el-Kebir, Algerien) ersäufen ließ. So berichtet es zumindest Victor, der Bischof von Vita in seiner Historia persecutionis Africanae provinciae, die keine Gelegenheit ausließ, die Vandalen als recht- und gesetzlose wilde Barbaren darzustellen. ${ }^{9}$ Ältere Interpretationen wollten in solchen Verteilungskämpfen in der neuen Militärelite Nordafrikas einen Bruch mit althergebrachten, germanischen' Freiheiten sehen. Solche Deutungsmuster haben ihre Wurzeln in der frühen Neuzeit und waren etwa für Conrad Mannert (1756-1834), der im letzten Viertel des 18. Jahrhunderts die erste Geschichte der Vandalen in deutscher Sprache verfasst hatte, gängig. „Vielleicht war die Zusammenverschwörung zum Besten dieser Familie unternommen, und dadurch veranlasst worden, dass Geiserich über seine Vandalen unumschränkter herrschte, als es deutsche Nationen von ihrem Anführer gewohnt waren. “" ${ }^{10}$ Freie ,Germanen“ mit einer altehrwürdigen ,Stammesorganisation' und einem sich konstituierenden, sozusagen protomittelalterlichem Königtum samt ,Dienstadel' standen den Römern als wesensfremde Eroberer gegenüber. So sah es die Forschung bis in die jüngere Vergangenheit. Auch für Ernst Stein, der 1928 den ersten Band seiner wegweisenden Geschichte der Spätantike vorlegen konnte, bevor er Deutschland und Österreich verlassen musste, bestand dahingehend keinerlei Zweifel. „Die Art, wie er [i. e. Geiserich] die Herrscherrechte auffasste und übte, führte im selben Jahr 442, in dem er mit den Römern Frieden schloss, zu Verschwörungen unter dem vandalischen Adel, deren Aufdeckung es dem König ermöglichte, durch zielbewusstes, auch das Königsgeschlecht nicht verschonendes Wüten jede Opposition im Blute zu ersticken und mit der alten germanischen Volksfreiheit bei den Vandalen vollends aufzuräumen. "11

Geiserichs Handeln unterschied sich nicht von dem anderer führender politisch-militärischer Protagonisten im spätrömischen Reich des fünften Jahrhunderts, die Macht und Besitz konzentrieren und dadurch auf einer hohen Ebene der Reichspolitik mitspielen wollten. Ein Vergleich seiner Person wäre also eher mit Ricimer, Aetius, Stilicho, Aspar oder dem dalmatinischen Marcellinus sinnvoll. Durch das erfolgreiche Ausschalten kleinerer Konkurrenten in

ab eo suppliciis excruciati atque extincti sunt. Cumque idem audendum etiam ab aliis videretur, tam multis regis suspicio exitio fuit, ut hac sui cura plus virium perderet quam si bello superaretur. Vgl. Ludwig Sснміdт, Geschichte der Wandalen, Leipzig - München 1942, S. 74.

9 Vict. Vit. (wie Anm. 4) 2, 14. Zu Victors Historia vgl. nun Tankred Howe, Vandalen, Barbaren und Arianer bei Victor von Vita (Studien zur Alten Geschichte 7) Frankfurt am Main 2007.

10 Conrad Mannert, Geschichte der Vandalen, Leipzig 1785, S. 68.

11 Ernst Stein, Geschichte des spätrömischen Reiches I, Wien 1928, S. 485. 
seinem eigenen Militärapparat konnte er seinen Nachfolgern einen immensen Fideikommiss hinterlassen, der eine beachtliche Machtstellung des hasdingischen Hauses im Mittelmeerraum des 5. und 6. Jahrhunderts ermöglichen sollte.

\section{Arianismus als politisches Instrument?}

Warum das in den katholischen Quellen so scharf geschilderte Beharren der vandalischen Könige auf einer Variante der homöischen Trinitätslehre, das im Hintergrund der hier zu besprechenden öffentlichen religiösen Auseinandersetzungen am vandalischen Hof stand? Hier ist nicht der Ort, um die für uns Historikerinnen und Historiker ohne besonderen Hintergrund nicht einfach zu verstehenden theologischen Probleme des spätantiken Diskurses in der nötigen Tiefe zu erörtern. Es sei in diesem Zusammenhang auf die Arbeiten von Knut Schäferdiek, Hanns C. Brennecke, Uta Heil und Christoph Markschies verwiesen. Einige grundlegende Sachverhalte müssen aber vorgebracht werden.

Arius hatte gegen den im Ägypten seiner Zeit verbreiteten Manichäismus argumentiert. Die Transzendenz Gottes sollte dabei betont werden. So wurde der Logos des Schöpfers, also vereinfacht gesagt Jesus Christus und der heilige Geist, ebenfalls als geschaffen und nicht ewig definiert. Damit war dieser Logos nicht mehr gleichwertig mit dem Vater. Arius schloss, radikaler als seine Vorgänger oder auch Wulfila und das Konzil von Rimini 359, jede Gleichheit des Vaters und des Sohnes aus. An diesem Grundproblem entzündete sich die theologische Auseinandersetzung. ${ }^{12}$

Der ,Bischof der Christen im Gotenland' Wulfila vertrat eine solchermaßen hierarchisch abgestufte Trinitätslehre, allerdings weniger nach Arius, sondern orientiert an der noch zu erörternden Formel der Reichskonzilien von Rimini und Seleukia. Gottvater ist in dieser Variante aller Gott und der einzige und daher auch der Gott unseres Gottes, also Christus. So liest sich das Glaubensbekenntnis in der Fassung des Wulfila. Die den Vandalen nahe stehenden Kleriker dürften diese Position geteilt haben. Kaiser Konstantin I. hatte politisches Interesse an einer einigen und entsprechend in seiner Machtpolitik instru-

12 Generell: Christoph Markschies, Alta trinità beata. Gesammelte Studien zur altkirchlichen Trinitätstheologie, Tübingen 2000, S. 124-131; Adolf-Martin RitTer, Arianismus, in: Theologische Realenzyklopädie 3 (1978) Sp. 692-719; Dokumente zur Geschichte des arianischen Streites, Athanasius Werke 3, 1-3, ed. Hanns C. Brennecke - Uta HeIL Annette von Stockнausen - Angelika Wintjes, Berlin - New York 2007, S. XIX-XXXVIII; Uta Heıl, „... bloß nicht wie die Manichäer!“ Ein Vorschlag zu den Hintergründen des arianischen Streits, in: Zeitschrift für Antikes Christentum 6 (2002) S. 299-319; Knut SchäfERdieK, Wulfila. Vom Bischof von Gotien zum Gotenbischof, in: Zeitschrift für Kirchengeschichte 90 (1979) S. $107-146$. 
mentalisierbaren Kirche. Er berief das erste Reichskonzil in seiner Sommerresidenz Nicaea ein. Gottvater sollte als einer Substanz mit Christus bezeugt

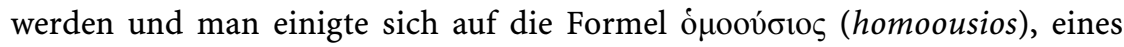
Wesens mit dem Vater. Nach der Verurteilung der Lehren des Arius auf dem Konzil von Nicaea 325 war die theologische Problematik eigentlich nicht gelöst, ja das nicaeanische Dogma war regelrecht ,arianisch' interpretierbar. Die Diskussion verschob sich zur Frage, „ob man hinsichtlich der Trinität nun von einer oder von drei göttlichen Hypostasen/Ousien zu reden, also stärker die Einheit oder die Dreiheit in der Trinität zu betonen habe. “13

Nach 325 konnte - und dies ist entscheidend für das Verständnis der späteren Bedeutung der homöischen Christologie bei militärischen Verbänden im spätrömischen Milieu - eine von Nicaea abweichende Lehrmeinung noch einmal die erste Ebene der Macht im Reich berühren. Vor dem Hintergrund des Versuchs des Constantius II. erneut kirchliche Einheit zu schaffen, gewannen verschiedene, die Trinität doch hierarchischer interpretierende, Lehrmeinungen wieder an Boden. Im Umfeld dieses Kaisers wurde die komplexe Beziehung von GottVater und Gott-Sohn auf den Konzilien von Ariminium (Rimini) und Seleukia im Jahre 359 „nun unter Vermeidung der als unbiblisch denunzierten Begriffe

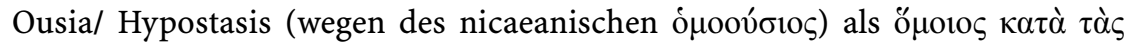

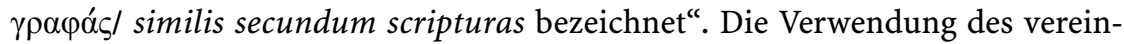
fachenden Begriffs ,Arianismus“ ist deshalb problematisch, weil dieser eigentlich aus der katholischen Polemik gegen solche Formulierungen stammt und unpräzise bleibt. ${ }^{14}$ Im Folgenden wird an einigen Passagen aus der Verfolgungsgeschichte des Victor von Vita zu zeigen sein, wie barbarische ,Arianer' regelrecht als Heiden stilisiert werden konnten.

Zurück in den Kontext der imperialen Kirchenpolitik und ihrer Konsequenzen. Erst Kaiser Theodosius I. erreichte mit rigorosen Maßnahmen Klarheit. 380 erhob er die katholische Orthodoxie nach der Lehrmeinung der Bischöfe von Rom und Alexandria zur alleinigen Staatsreligion. Die Ergebnisse der

13 Zitat: Hanns Christof BRENneCKe, Lateinischer oder germanischer'Arianismus'? Zur Frage einer Definition am Beispiel der religiösen Konflikte im nordafrikanischen Vandalenreich, in: Collatio Augustini cum Pascentio. Einleitung, Text. Übersetzung, hg. von Hildegund MÜLLER - Dorothea Weber - Clemens WeIdmann (Sitzungsberichte der phil.-hist. Klasse 779. Veröffentlichungen der Kommission zur Herausgabe des Corpus der lateinischen Kirchenväter 24) Wien 2008, S. 135 - 144, hier S. 126 f. Zum Bekenntnis Wulfilas vgl. ebd. 139 ff. und SCHÄFERDIEK, Wulfila (wie Anm. 12) S. 134 ff. Zu Nicaea vgl. MARKsChiEs, Alta trinità beata (wie Anm. 12) S. 134-164.

14 Zitat: Brennecke, ,Arianismus' (wie Anm. 13) S. 129 f.; H. C. Brennecke, Studien zur Geschichte der Homöer (Beiträge zur historischen Theologie 73) Tübingen 1988, S. 5-22; MARKschies, Alta trinità beata (wie Anm. 12) S. 290; Peter J. HeATher, Christianity and the Vandals in the Reign of Geiseric, in: Wolf Liebeschuetz reflected: essays presented by colleagues, friends \& pupils, hg. von John F. Drinkwater - Benet Salway (Bulletin of the Institute of Classical Studies. Supplement 91) London 2007, S. 137-146. 
Synode von Konstantinopel von 381 festigten die katholische Trinitätslehre und gaben ihr alleinige Gültigkeit. Christus und der heilige Geist wurden als zweite und dritte Hypostase Gottes kanonisiert, ein Gott in drei Personen sich manifestierend also. Die nach Nicaea aufgetretenen Probleme mit der traditionellen Subordinationstrinität - die ja auch unabhängig von Arius bestanden hatten wurden dadurch vermieden, dass man zwar drei verschiedene Hypostasen/ subsistentiae definierte, die aber doch ein Gott waren. Die Beschlüsse von Rimini/Seleukia des Jahres 359 galten von nun an als häretisch. Es wurde eng für Vertreter einer abweichenden Christologie. Konstantinopel hatte allerdings in einer ersten Phase nur Gültigkeit für den von Theodosius beherrschten Osten. Der mächtige Bischof von Mailand und Vertreter einer katholischen Trinitätslehre, Ambrosius, bemühte sich, im selben Jahr in Aquileia eine lateinische und westliche Synode zu organisieren. Nun wurden auch die lateinischen Homöer als eben ,arianische' Häretiker aus dem Kirchenverband geworfen. Es bildeten sich lateinische homöische Gruppierungen, die sich auf das kurze Bekenntnis von Rimini beriefen. Kurz sei noch erwähnt, dass in Illyricum, wo sich lateinische und griechische Kultur - und eben auch theologische Debatte - intensiv berührten, in diesem Zusammenhang wesentliche homöische Aktivitäten und Texte zu verorten sind. ${ }^{15}$

Vor dem Hintergrund des letzten Viertels des 4. Jahrhunderts kam es nun zu den entscheidenden Entwicklungen. Das theodosianische Regime hatte sich klar für den katholischen Mainstream - repräsentiert von Ambrosius und später Augustinus - entschieden. Theologische Fragen waren politisch aufgeladen. Eine dritte Gruppe von Mächtigen, neben der Senatsaristokratie und der katholischen Kirche, begann im römischen Reich ihre Rolle einzunehmen: barbarische Militärs respektive militärische Verbände wie Goten und Vandalen. ${ }^{16}$

Homöische Trinität wurde eine Spielart der Theologie, die prestigeträchtige gotische und andere barbarische Gruppen (und eben auch die Vandalen) in den letzten Jahrzehnten des 4. Jahrhunderts im Osten des römischen Reiches und im Illyricum vorfanden und der sie sich anschlossen. Man könnte es folgendermaßen auf den Punkt bringen: Föderaten- und Barbarenverbände verpassten durch ihre gesellschaftliche und juristische Sonderstellung einen reichsweit

15 Markschies, Alta trinità beata (wie Anm. 12) S. 304-307; Christoph Markschies, Ambrosius von Mailand und die Trinitätstheologie. Kirchen- und theologiegeschichtliche Studien zu Antiarianismus und Neunizänismus bei Ambrosius und im lateinischen Westen 364-381 n. Chr. (Beiträge zur historischen Theologie 90) Tübingen 1995; Hartmut LEPPiN, Theodosius der Große, Darmstadt 2003, S. 133 - 155; Hartmut LEPPIN, Von Constantin dem Großen zu Theodosius II. Das christliche Kaisertum bei den Kirchenhistorikern Socrates, Sozomenus und Theodoret (Hypomnemata. Untersuchungen zur Antike und zu ihrem Nachleben 110) Göttingen 1996.

16 Brennecke, ,Arianismus' (wie Anm. 13) S. 129. 
vollzogenen theologischen Schritt, nämlich den von Nicaea nach Konstantinopel. Sie hingen weiterhin der Mitte des 4. Jahrhunderts akzeptierten und legalen Reichstheologie an. Dazu denken muss man sich weiters in den lediglich 20 Jahren zwischen Rimini und Konstantinopel orientierungslos gewordene Geistliche, die in den neuen militärischen Machthabern nun ihre Patrone fanden. Vertreter des nach 381 als häretisch geltenden und verbotenen lateinischen ,Arianismus' konnten bei den barbarischen Militärs als Priester oder Bischöfe nicht nur weiter ihren Glauben leben, sondern auch Karriere machen. Ein Beispiel für eine solche Persönlichkeit wäre der arianische Bischof Maximinus, der mit Augustinus einen Disput führte und für Geiserich tätig war. „Die auf Reichsboden angesiedelten Goten wurden in den folgenden Jahrzehnten zum Kristallisationskern der Christianisierung der ins Reich kommenden ganz unterschiedlichen germanischen Gruppen. ${ }^{\text {“17 }}$

Solche Militärverbände übernahmen eine homöische Christologie als ihren römischen, apostolischen Glauben und in relativ kurzer Zeit bedeutete ein Soldat barbarischer Herkunft zu sein, sich gleichzeitig als Christ am Dogma des Konzils von Rimini bzw. Seleukia zu orientieren. Ein weiterer Punkt steht zu bedenken: Föderaten unterstanden explizit nicht den strengen Religionsgesetzen, die das Regime des Theodosius formuliert hatte. Barbarische römische Truppenkontingente konnten also auch nach 381 ganz legal innerhalb der Reichsgrenzen ,Arianer' bleiben. Spekulationen darüber, wann die Vandalen denn das Christentum angenommen hätten, erübrigen sich dann, wenn man die Vandalen wie die Goten als Militärverband von der römischen Peripherie begreift. Die Führungsebene barbarischer Militärverbände organisierte sich häufig nach christlichem Muster und unter Beteiligung homöischer Geistlicher. Während der Kämpfe von 422 gegen den römischen Feldherren Castinus sollen die Vandalen die Bibel gegen ihre römischen Gegner gehalten und gerade so wie die Stimme Gottes Offenbarungen des Heils gegen die römischen Truppen gerufen haben. Weiter meint Salvianus, dass die Römer die Goten und Vandalen Ketzer nennen und selbst nicht besser seien. Allerdings verstehe man an den Fakten, wie der Schöpfer die Dinge sehe: Die Barbaren wachsen von Tag zu Tag, die Römer dagegen entwickeln sich zurück. Die Barbaren blühen, die Römer verwelken. „Das bedeutet wohl nicht mehr oder weniger als dass Salvianus die Vandalen zu Soldaten Christi hochstilisierte. ${ }^{\text {“18 }}$

17 Zitat: Brennecke, ,Arianismus' (wie Anm. 13) S. 137; vgl. weiters Knut SchäFerdieK, Schwellenzeit. Beiträge zur Geschichte des Christentums in Spätantike und Frühmittelalter, hg. von Winrich A. LÖHR - Hanns C. BRENNECKE (Arbeiten zur Kirchengeschichte 64) Berlin - New York 1996; Ralph W. Mathisen, Sigisvult the Patrician, Maximinus the Arian, and political strategems in the Western Roman Empire c. 425 - 440, in: Early Medieval Europe 8/2 (1999) S. 173- 196.

18 Salvianus von Marseille, De Gubernatione Dei 7, 26-28, ed. Karl Halm (MGH AA 1) Berlin 
Als solche Militärverbände im Laufe des 5. Jahrhunderts die politische Macht und die Verwaltung römischer Provinzen übernahmen, kam es zu neuen Entwicklungen, die, was die Westgoten betrifft, erst mit dem Konzil von Toledo 589 und der Akzeptanz des katholischen Glaubens durch die Frankenkönige ein Ende fanden. Im 5. Jahrhundert verhielten und organisierten die Nachfolgereiche unter barbarischen Königen sich ja in gewisser Weise wie ein Teil des Imperiums und die Herrscher in den ehemaligen Provinzen wie Lokalkaiser. Die Vandalenkönige trachteten etwa danach, auch in der Religionspolitik zwar römische, aber eben doch regionale Wege zu gehen. Knut Schäferdiek hat in diesem Zusammenhang von ,arianischen Landeskirchen' gesprochen. ${ }^{19}$

Die wenigen in gotischer oder lateinischer Sprache erhaltenen homöischen Texte und Fragmente bestätigen die enge Beziehung zu Rimini/Seleukia. Die gotische Liturgie und Bibel dürfen aber keineswegs als einer irgendwie gearteten germanischen Kultur entsprechend verstanden werden, sondern sind nichts anderes als Konsequenzen einer in den Ostkirchen ganz selbstverständlichen Vielheit von Liturgiesprachen. Vor einem solchen Kontext kann das aus der Collatio sancti Augustini cum Pascentio Arriano bekannte so genannte, vandalische' froja arme für Domine miserere verstanden werden..$^{20}$ Der Text enthält eine gotische Formulierung und einen Gedankengang über die Zulässigkeit verschiedener Liturgiesprachen: „Darf also dieses Erbarmen vom einen Gott selbst, dem Vater, dem Sohn und dem Heiligen Geist allein in hebräischer, griechischer oder zuletzt sogar in lateinischer Sprache erbeten werden, nicht aber auch in einer Barbarensprache (lingua [...] non autem et barbara)? Denn wenn nicht nur die Barbaren in ihrer Sprache, sondern auch die Römer ,Froja arme' sagen dürfen, was die Übersetzung von ,Domine miserere' ist, warum hätte man dann nicht auf den Konzilien der Väter im Land der Griechen selbst, von wo aus das Glaubensbekenntnis überallhin seinen Ausgang nahm, in deren eigener Sprache das Homousion bekennen dürfen, (...).“21

\footnotetext{
${ }^{2} 1961$, S. 1 - 108, hier S. 88 - 89; Helmut Castritius, Die Vandalen. Etappen einer Spurensuche (Kohlhammer-Urban-Taschenbücher 605) Stuttgart 2007, S. 10 - 11 (Zitat); vgl. Knut SCHÄFERDIEK, Germanenmission, in: Reallexikon für Antike und Christentum, Bd. 10 (1978) Sp. 492 - 548, hier Sp. 497-519; BrenneCKe, ,Arianismus' (wie Anm. 13) S. 137.
}

19 SCHÄFERDIEK, Germanenmission (wie Anm. 18) Sp. 497-519.

20 Schäferdiek, Germanenmission (wie Anm. 18) Sp. 497-501, vgl. dort zum froja armes S. 507.

21 Collatio Augustini cum Pascentio 15, ed. und übers. Müller - Weber - Weidmann (wie Anm. 13) S. 114 f. Der Stand der Forschung zum ,Vandalischen', das vor allem aus Namenmaterial postuliert wird: Hermann Reichert, Die Sprache der Wandalen in Afrika und „Auch Römer dürfen froia arme für domine miserere sagen“, in: MülLER - Weber Weidmann (wie Anm. 13) S. 145-172; Nicoletta Francovich Onesti, I Vandali. Lingua e storia (Lingue e letterature Carocci 14) Roma 2002; Leslie Dossey, The last days of Vandal Africa. An Arian commentary on Job and its historical context, in: Journal of Theological Studies 54 (2003) S. 60 - 138, hatte versucht, einen anonymen Hiobkommentar als im van- 
Die Frage, ob es überhaupt eine eigenständige vandalische Sprache gegeben hat, ist letztlich von der Germanistik zu beantworten. Festzustellen bleibt, dass keine Quelle explizit von einer solchen zu berichten wüsste. Unter historischen Gesichtspunkten würde es nicht verwundern, hätte im vandalischen Nordafrika lediglich in der homöischen Liturgie das Gotische Verwendung gefunden.

Die vandalischen Könige scheinen sich in verschiedenen Bereichen ganz wie kleine Kaiser verhalten zu haben. Bei der Neuorganisation der afrikanischen Provinzen wurde nun aus machtpolitischen Überlegungen auf die arianische Karte gesetzt und schnell gerieten die karthagischen Könige dadurch in Konfrontation mit den zwei traditionellen Eliten. Es handelte sich dabei um die theologisch nach Nicaea und Konstantinopel formierte Reichskirche und die Senatsaristokratie, die in Afrika über enge Beziehungen nach Italien verfügte bzw. sich in vielen Fällen gar aus italischen Familien rekrutierte. Eine staatlich gelenkte Kirche war in den Mustern spätantiker Politik nichts Ungewöhnliches. Erneut sei der Name des in der katholischen Literatur mit dem Epitheton,der Große' versehenen Kaisers Theodosius I. genannt. Wie Theodosius oder Konstantin beriefen die Vandalenkönige Konzilien ein und die afrikanischen Bischöfe folgten diesen Befehlen und versammelten sich in Karthago. ${ }^{22}$

Obadus, der praepositus regni, fragt den Bischof Eugenius, ob der Kirchenmann denn dem König gleichwertig sei, nachdem dieser königliche Anordnungen zu diskutieren begonnen hatte. Eugenius hatte verlangt, für das so genannte Religionsgespräch in Karthago 484 katholische Autoritäten auch aus anderen Provinzen zuzuziehen. Hunerich ließ nur bestellen, erst wenn der Bischof den ganzen Erdkreis (universis orbis terrarum) seiner königlichen Gewalt unterstellen könne, werde er solches erlauben. Die religiöse Frage war also untrennbar mit der Frage nach der Macht im Staat gekoppelt. ${ }^{23}$ Als katholische Bischöfe von König Hunerich aufgefordert werden, auf Hilderich als Nachfolger zu schwören, zögern diese. Mit Hunerichs Wunsch nach der Thronfolge seines Sohnes würde Geiserichs Thronfolgeordnung durchbrochen. Das Vorgehen des Königs war in diesem Punkt also innen- wie außenpolitisch problematisch.

dalischen Nordafrika entstanden zu deuten. Dagegen nun mit überzeugenden Argumenten Kenneth B. Steinhauser, Introduction, in: Anonymi in Iob Commentarius, hg. von Kenneth B. Steinhauser - Hildegund Müller - Dorothea Weber (Corpus Scriptorum Ecclesiasticorum Latinorum 96) Wien 2006, S. 9-84, hier S. $38 \mathrm{ff}$.

22 Brennecke, ,Arianismus' (wie Anm. 13) S. 142 f.; Christoph Markschies, Kaiserzeitliche christliche Theologie und ihre Institutionen. Prolegomena zu einer Geschichte der antiken christlichen Theologie, Tübingen 2007; Adolf LipPold, Theodosius der Große und seine Zeit, München ${ }^{2} 1980$, S. 7, 138, Anm. 1.

23 Vict. Vit. (wie Anm. 4) 2, 43 - 44; vgl. Howe, Vandalen, Barbaren und Arianer (wie Anm. 9) S. 215 und Anm. 75, S. 280 f.; Jörg Spielvogel, Arianische Vandalen, katholische Römer: die reichspolitische und kulturelle Dimension des christlichen Glaubenskonflikts im spätantiken Nordafrika, in: Klio 87/1 (2005) S. 201 -222, hier S. 209 f. 
Weiters sollten die katholischen Bischöfe versprechen, keine Korrespondenz in überseeische Gebiete zu unterhalten. ${ }^{24}$

Die theodosianische Dynastie hatte nie die Ressourcen der Senatsaristokratie, der sie elementar verpflichtet war, angetastet. Geiserich tat das schiere Gegenteil und enteignete in seinem Machtbereich nicht nur den Kaiser, sondern auch die großen Güter der bisherigen Eliten. Mit hoher Wahrscheinlichkeit war auch die katholische Reichskirche von solchen Enteignungen betroffen. In beiden Fällen des vandalischen Vorgehens gegen die afrikanischen Großen wurde politisch das Funktionieren der Provinzen durchgesetzt wie der Machtwechsel gesichert. Das Unterbinden von Beziehungen nach Übersee ist in diesem Zusammenhang zu verstehen. Solche Maßnahmen gehören zur Basis des Modells der Umgestaltung von Provinzen zu einem Regnum. In beiden Fällen erwies sich das als konfliktreich. Die angestrebte königliche Autorität über die katholische Kirche in den afrikanischen Provinzen wurde für mehrere Jahrzehnte ein wesentliches politisches Problem. Die Vandalenkönige versuchten ihre eigene, homöische Landeskirche als Alternative, wenn nicht gar als Ersatz für die Reichskirche zu positionieren.

Ob diese Vorgänge sich vor allem auf die Proconsularis bezogen ist nicht gänzlich geklärt und hängt eng mit einer Definition der bei Victor so bezeichneten sortes Vandalorum zusammen. Victors Verfolgungsgeschichte berichtet jedenfalls von Verboten der katholischen Kultausübung in sortibus Vandalorum und überhaupt konzentrieren sich die Verfolgungen dort. Generell war der bisherige Zugang der Forschung in diesem Punkt meist von einer Idee der Ansiedlung von Vandalen in den sortes so stark beeinflusst, dass es notwendig erscheint, die Debatte neu zu führen. Ob es sich um besondere Rechtsverhältnisse gehandelt haben mag, bleibt eine Möglichkeit. Denkbar wäre etwa eine Zentrierung enteigneten kaiserlichen und senatorischen Grundbesitzes unter besonderer königlicher possessorischer Gewalt in der Proconsularis. Parallel dazu befand sich das Hausgut der Hasdingen in der Byzacena und anderen Provinzen Afrikas. Das würde bedeuten, die sortes hätten die Funktion gehabt, für den Lebensunterhalt von Soldaten aufzukommen. Hier ist größte Vorsicht geboten und die Debatte wird mit unverminderter Heftigkeit geführt. ${ }^{25}$

24 Vict. Vit. (wie Anm. 4) 3, 19; vgl. Yves Modéran, Une guerre de religion. Les deux Eglises d'Afrique à l'époque vandale, in: Antiquité Tardive 11 (2003) 21 -44; Dietrich Claude, Probleme der vandalischen Herrschaftsnachfolge, in: Deutsches Archiv 30 (1974) S. 329355.

25 Vict. Vit. (wie Anm. 4) 2, 39; 3, 4; Dazu in Vorbereitung das Kapitel „Die sortes Vandalorum/ kleroi Bandilon und die Organisation der Provinzen nun unter vandalischer Herrschaft" in VERF. „Die Vandalen. Ein spätrömisches Königreich in Nordafrika“. Die Diskussion ist nur scheinbar neu und dreht sich seit Felix Dahn, Die Könige der Germanen. Das Wesen des ältesten Königthums der germanischen Stämme und seine Geschichte bis zur Auflösung des karolingischen Reiches. Bd. 1/2 Die Vandalen, München 1861, S. 189, 204 ff. mit Anm. 7 im 
Wolf Liebeschuetz hat betont, dass religiöse Fragen, wie man am Beispiel des byzantinischen Reiches oder in der jüngeren Vergangenheit in Griechenland, Irland oder Polen sehen kann, wichtige Faktoren bei der Entstehung regionaler, ethnischer oder gar nationaler Identitäten sein können. Weiters sei es schwer vorstellbar, dass Persönlichkeiten wie Alarich, Geiserich oder Theoderich die konfessionelle Sonderstellung ihrer Krieger nicht ganz bewusst als Element politischer Machtausübung einzusetzen trachteten. Liebeschuetz vermutet, der Übertritt ins arianische Bekenntnis könnte zumindest ein wesentlicher Schritt gewesen sein, in die vandalische gens aufgenommen zu werden. ${ }^{26}$

Warum der konfessionelle Konflikt solche Dimensionen annehmen konnte, lässt sich mit einem Brief aus einem gallischen Kontext illustrieren. Sidonius Apollinaris wandte sich an den Bischof Basilius, um ihm politische Ratschläge zu geben. Sidonius empfahl dem Kirchenmann, die römischen Verhandlungsführer mögen den westgotischen König Eurich dazu bringen, auf die Einsetzung von Bischöfe keinen Einfluss zu nehmen „damit wir die Völker Galliens, die im gotischen Gebiet leben, wenn nicht mit dem Foedus, so doch aus dem Glauben heraus, behaupten können “. ${ }^{27}$ Eine im gesamten Mittelmeerraum organisierte Reichskirche stand dem Versuch, eine römische Provinz als regnum zu gestalten, entgegen. Insofern wird das oben erwähnte Verbot des Vandalenkönigs gegenüber den katholischen Bischöfen, überseeische Korrespondenz zu unterhalten, besser verständlich. Die angesprochenen Vorgänge „müssen so als religiös motivierte und ausgetragene politische Loyalitätskonflikte zwischen Römern und Vandalen begriffen werden. Das sollte allerdings nicht dazu verführen, die religiösen Konflikte auf beiden Seiten nicht ernst zu nehmen. Beiden ging es auch um Glaubenswahrheiten, wie für die Seite der arianischen Vandalen gerade auch theologische Thesen Thrasamunds zeigen. “28

Kreis. Vgl. jüngst Walter A. Goffart, The Technique of Barbarian Settlement in the Fifth Century. A Personal, Streamlined Account with Ten Additional Comments, in: Journal of Late Antiquity 3/1 (2010) S. 65-98.

26 John Hugo Wolfgang Gideon Liebeschuetz, Gens into Regnum: The Vandals, in: Regna and Gentes. The Relationship between Late Antique and Early Medieval Peoples and Kingdoms in the Transformation of the Roman World, hg. von Hans-Werner GoETZ - Jörg JARnUt Walter РонL (The Transformation of the Roman World 13) Leiden - Boston - Köln 2003, S. 55-83, hier S. 56. Ähnlich argumentiert Heather, Christianity and the Vandals (wie Anm. 14) S. $145 \mathrm{f}$.

27 Sidonius Apollinaris, Epistulae 7, 6, ed. Christian Luetjohann (MGH AA 8) Berlin ${ }^{2} 1961$, S. 110: Agite, quatenus haec sit amicitiae concordia principalis, ut episcopali ordinatione permissa populos Galliarum, quos limes Gothicae sortis incluserit, teneamus ex fide, etsi non tenemus ex foedere. Vgl. Herwig Wolfram, Die Goten. Von den Anfängen bis zur Mitte des sechsten Jahrhunderts. Entwurf einer historischen Ethnographie, München ${ }^{5} 2009$, S. 202 mit Anm. 22.

28 Brennecke, ,Arianismus` (wie Anm. 13) S. 141. 


\section{Der vandalische Hof als Ort der öffentlichen religiösen Auseinandersetzung}

Der Konflikt hatte sich zugespitzt, als Geiserich und Hunerich den Einfluss der katholischen Amtskirche systematisch zurückzudrängen begannen. Die Durchsetzung des arianischen Bekenntnisses unter loyalen römischen Mitarbeitern bot die Möglichkeit, die Basis der Vandalenherrschaft zu verbreitern und zumindest den systemrelevanten Teil der römischen Führungsschicht zu integrieren. Insofern sollte man die Vorgehensweise Geiserichs und Hunerichs als primär politisch motiviert analysieren. Erklärungen, die in der komplexen Christologie eine Nähe zu einem wie auch gearteten ,germanischen' Wesen sehen wollten, sind inzwischen gänzlich zurückgewiesen worden. Dass persönliche religiöse Überzeugungen und die Idee einer göttlichen Legitimation von Herrschaft, die allerdings wieder ein römisches Element wäre, ihre Rolle spielen, steht hier nicht zur Debatte. Der erzählerische und literarische Charakter der Quellen verführt dazu, individuelle Charakterzüge überzubetonen und den Hintergrund aus den Augen zu verlieren. ${ }^{29}$

Bisher wurde meist davon ausgegangen, dass Glaubensfragen lediglich einer ethnischen Abgrenzung der, germanischen' Vandalen in ihrem Regnum dienten. Es gab aber sehr wohl auch Vandalen, die Katholiken waren, deshalb blieben sie dennoch Vandalen. Zwei Vandalen geben bei Victor von Vita, im Rahmen der großen persecutio unter Hunerich, all ihren Besitz auf und gehen mit katholischen Priestern gemeinsam in die Verbannung. Sie waren schon unter Geiserich confessores. ${ }^{30}$ Nach der Eroberung Afrikas durch Justinians Truppen wird konvertierten Römern im öffentlichen Dienst, der militia, die Gelegenheit gegeben, sich erneut taufen zu lassen. Sie wurden als Häretiker, nicht aber als Vandalen behandelt. $^{31}$

437 wandte Geiserich erstmals direkt Gewalt gegen katholische Priester an. Er dürfte sich selbst als den führenden römischen Magistrat vor Ort definiert haben und zwar in jenen Gebieten, deren Kontrolle der Vertrag von 435 den Vandalen übertragen hatte. Geiserich führte keinen offiziellen römischen Titel, wie das Theoderich oder Chlodwig später taten, aber faktisch handelte er wie die Spitze der römischen Verwaltung zu handeln gewohnt war. Es war für lokale wie kaiserliche römische Machthaber in der Spätantike gänzlich normal, in theologi-

29 Brennecke, ,Arianismus' (wie Anm. 13) S. 142 f.; Heather, Christianity and the Vandals (wie Anm. 14) S. 144 f. Ein Beispiel für eine Überbewertung der Anekdoten: L. J. van der LoFT, Der fanatische Arianismus der Wandalen, in: Zeitschrift für die neutestamentliche Wissenschaft und die Kunde der älteren Kirche 64 (1973) S. 146-151.

30 Vict. Vit. (wie Anm. 4) 3, 38; vgl. Howe, Vandalen, Barbaren und Arianer (wie Anm. 9) S. 156 f. mit Anm. 1, S. 176 mit Anm. 85.

31 Corpus iuris civilis 3. Novellae 37, 10, ed. Rudolf SCHöLL - Wilhelm KroLL, Berlin ${ }^{12} 1988$. 
sche Streitigkeiten im eigenen Interesse einzugreifen. Das Interesse des vandalischen Königs war es, die arianische Kirche zu stärken und die katholische mit ihren überseeischen Verbindungen als ständige Bedrohung des Systems, das die Vandalen in Afrika formten, zu schwächen.

Geiserich erwartete, dass alle in seiner höfischen Umgebung dieser Kirche, die der königlichen Macht näher stand als allen anderen denkbaren, beizutreten hatten. Diese Forderung wurde mit drastischen Maßnahmen durchgesetzt, wie das Schicksal von fünf aus Spanien stammenden Römern im Hofstaat Geiserichs zeigt. Arcadius, Probus, Paschasius, Eutycianus und Paulillus, die sich, obwohl der König das als Loyalitätsbeweis forderte, nicht zum Arianismus bekennen wollten, wurden enteignet, verbannt und schließlich nach dem Versuch zurückzukehren mit Ausnahme des Paulillus, hingerichtet. Pseudo-Gennadius und ein Trostbrief des Bischofs Honoratus, der in Cirta (Constantia) residierte, berichten von diesen Vorgängen um $480 .^{32}$

Am karthagischen Hof betrafen diese Maßnahmen etwa die Gattin des königlichen Kellermeisters Dagila und den archimimus Mascula. Der Schauspieler und die Gattin des Hofbeamten wurden nach Victor zu Märtyrern, weil Geiserich den Übertritt zum Arianismus gefordert hatte und sie nach ihrer Weigerung hinrichten ließ. Die verfolgten afrikanischen Katholiken werden bei Victor immer wieder in Parallele zu den von heidnischen Kaisern verfolgten Christen gebracht. Zwei königliche comites versuchen die Bekenner mit Argumenten zur Konversion zu bringen. Diese rufen nur Christiani sumus und bekennen die katholische Trinität. Das Setting soll bewusst an die Schilderungen der Verfolgungen durch heidnische Kaiser des 3. Jahrhunderts erinnern. Den Vandalenkönigen wird dabei geschickt die Rolle der ungläubigen Unrechtsherrscher zugeschrieben. Die Vandalen werden bei Victor zu Ariani und damit wird ihnen eigentlich ihr Christentum abgesprochen. Auf zwei Ebenen agierten die Vandalenkönige wie römische Kaiser. In der Stilisierung Victors geben sie die Gelegenheit zum Martyrium. Das ist eine literarische Brechung. Tatsächlich wandten sie in zutiefst römischer Manier die Ketzergesetze des Theodosius I. wie seiner Vorgänger gegen die Arianer und andere Häretiker nun gegen die katholische Kirche selbst an. Victor spricht dies explizit aus. Hunerich habe sich nicht entblödet, gegen die afrikanischen Katholiken ein Gesetz anzuwenden, dass die eigenen Kaiser zur Ehre und zum Schutz der Kirche gegen diese, also die Vandalen, und andere Ketzer erlassen hatten. ${ }^{33}$

32 Pseudo-Gennadius, De viris inlustribus 96, ed. Jean-Paul Migne (PL 50) Paris 1846, S. 567; vgl. Sснмidt, Geschichte der Wandalen (wie Anm. 8) S. 66; Andreas Schwarcz, Religion und ethnische Identität im Vandalenreich. Überlegungen zur Religionspolitik der vandalischen Könige, in: Das Reich der Vandalen, hg. von Berndt -Steinacher (wie Anm. 2) S. $227-232$.

33 Vict. Vit. (wie Anm. 4) 1, 47; 2, 28; 3, 2; 3, 3-14; 3, 33; Codex Theodosianus, 16, 5, 16-66, 
Victor von Vita zählt als eine der Behinderungen der afrikanischen Katholiken auf, Geiserich habe verboten den Pharao, Nebukadnezar, Holofernes, Herodes oder ähnlich konnotierte biblische Persönlichkeiten irgendwie zu erwähnen. ${ }^{34}$ Victor beendet das folgende Kapitel dann mit einer Anspielung auf die Exodusstelle die Israeliten betreffend, welche vom Pharao bedrängt werden, die an Deutlichkeit nicht zu überbieten ist: Quanto eos affligebant, tanto magis multiplicabantur et invalescebant nimis. ${ }^{35}$ Metaphern des katholischen Diskurses wurden vom vandalischen Apparat aus dem Spiel genommen. Der Vandalenkönig hatte verboten, ihn mit den großen biblischen Verfolgern des Volkes Gottes zu vergleichen. Nun ist dies auf der einen Seite eine Maßnahme gegen mögliche antikönigliche Propaganda, auf der anderen aber interpretierbar als nicht geringer Machtanspruch in der Symbolik des christlich gewordenen Mittelmeerraumes. Jedenfalls viel mehr als sich die Vorfahren des Barbarenkönigs Geiserich jemals hätten erwarten können. Der Gegner im Kampf um die Macht, die katholische Kirche, revanchierte sich auf seine Weise in sehr nachhaltiger Form. Victor von Vita beendet seine Historia persecutionis mit einem Bericht vom Tod des Sohnes Geiserichs, Hunerich, am 22. Dezember 484. Würmer sollen aus dem Leib des noch lebenden Königs hervorgebrochen sein, der Leib begann zu faulen und man musste schließlich den in Teile zerfallenen Körper bestatten. ${ }^{36}$

Geiserich erging es kaum besser. Auch donatistische und andere christliche Gruppen in Nordafrika wurden verfolgt. Hier verhielten sich die Vandalenkö-

edd. Theodor Mommsen - Paul KrÜger - Paul M. Meyer, Hildesheim ${ }^{2} 2005$. Ein detaillierter Nachweis der Bezüge findet sich bei Mechthild OverвecK, Untersuchungen zum afrikanischen Senatsadel in der Spätantike (Frankfurter althistorische Studien 7) Frankfurt/ Main 1973, S. 74 - 82. Vgl. dazu Howe, Vandalen, Barbaren und Arianer (wie Anm. 9) S. 170 und Anm. 53, S. 172 f.; Einen Überblick über die Verfolgungen bieten: Yves ModÉRAN, L'Afrique et la persécution vandale, in: Histoire du Christianisme des origines à nos jours Bd. 3. Les Églises d'Orient et d'Occident, hg. von Jean-Marie MAYeur - Charles PIÉtri André Vauchez - Marc Venard, Paris 1998, S. 247 - 278; Hans-Joachim Diesner, Vandalen, in: RE Suppl., Bd. 10 (Stuttgart 1965) Sp. 957 - 992, hier Sp. 962 - 969; Heather, Christianity and the Vandals (wie Anm. 14); Konrad Vössing, 'Barbaren' und Katholiken. Die Fiktion der Collatio sancti Augustini cum Pascentio Arriano und die Parteien des vandalischen Kirchenkampfes, in: Collatio Augustini cum Pascentio, hg. Von Müller - Weber - WeIdmanN (wie Anm. 4) S. 173 - 206, hier S. 181 - 188; SpIelvogel, Arianische Vandalen (wie Anm. 23) S. 204 -211; Courtors, Les Vandales (wie Anm. 5) S. 223 ff., 289-310; Schмidt, Geschichte der Wandalen (wie Anm. 8) S. $102-113$.

34 Vict. Vit. (wie Anm. 4) 1, 22 und 23; vgl. Pierre Courcelle, Histoire littéraire des grandes invasions germaniques, Paris 1964, S. 137 und Anm. 1; Courtors, Les Vandales (wie Anm. 5) S. 86.

35 Vict. Vit. (wie Anm. 4) 1, 23; Ex I, 12: Quantoque opprimebant eos tanto magis multiplicabantur et crescebant.

36 Vict. Vit. (wie Anm. 4) 3, 71; vgl. Steinacher, Gruppen und Identitäten (wie Anm. 2) S. 251; Ders., Von Würmern bei lebendigem Leib zerfressen ... und die Läusesucht Phtheiriasis. Ein antikes Strafmotiv und seine Rezeptionsgeschichte, in: Tyche 18 (2003) S. 145-166. 
nige erneut gemäß ihren kaiserlichen Vorbildern. Im Liber Genealogus, einer donatistischen Redaktion biblischer Informationen auf Basis der Chronik des Hippolyt von Rom, wird Geiserichs nomen Gothice nach den Zahlenwerten der griechischen Schreibung als die Zahl 666 des Antichristen beinhaltend enttarnt. Kurz zuvor in diesem Text wird selbiges mit dem Namen Neros vorgerechnet. Auch hier wurde ein Vandalenkönig also wieder mit Verfolgerkaisern gleichgesetzt. $^{37}$

Homöische Kleriker und vandalische Große sahen ihre Kirche allerdings als die universelle, einzige, apostolische und katholische, gerade wie die Reichskirche auch. Der Patriarch Cyrila sitzt bei Victor während der Religionsgespräche in Karthago auf einem Thron, während die katholischen Bischöfe stehen müssen. Auch weigert er sich Latein zu sprechen - letzteres wohl eher als Provokation denn in Unkenntnis der liturgischen wie theologischen Basis. Trotzdem stilisiert ihn Victor zum barbarischen Außenseiter : „Unsere Leute änderten ihre Taktik und sagten zu Cyrila: Argumentiere, was Du zu tun gedenkst. Cyrila antwortete: Nescio Latine. Unsere Bischöfe sagten: Wir wissen ganz genau, dass Du immer Latein gesprochen hast, nun solltest Du Dich nicht so herausreden, gerade weil Du dieses Feuer angezündet hast." Cyrila soll mit seiner schnell entlarvbaren Ausrede als der Dumme stehen bleiben, wie an so vielen Stellen in Victors Text. Immerhin aber wird klar, dass beide Seiten Latein als Sprache der theologischen Auseinandersetzung zu verwenden gewohnt waren. ${ }^{38}$

37 Liber Genealogus F 618, ed. Theodor Mommsen (MGH AA 9, CM 1) Berlin ${ }^{2} 1981$, S. $154-$ 196, hier S. 195. Diese Zuweisung findet sich in der Florentiner Handschrift des Liber Genealogus. Vgl. Sснмidt, Geschichte der Wandalen (wie Anm. 8) S. 192; Frank M. Clover, Felix Karthago, in: Dumbarton Oaks Papers 40 (1986) S. 1-16; repr. Frank M. Clover, The Late Roman West and the Vandals (Aldershot 1993) Text IX, S. 11 und Anm. 76. In einer Ergänzung eines späteren Redaktors im Kommentar zur Apokalypse des Johannes des Victorinus von Ptuj - Pettau erscheint diesselbe Rechnung mit Geiserichs Namen: Victorinus Petavionensis, Scholia in Apocalypsi beati Joannis 13, 18, ed. Jean-Paul Migne (PL 5) Paris 1844, S. $317-344$, hier S. 339.

38 Vict. Vit. (wie Anm. 4) 2, 53 - 55: Conversique nostri Cyrilae dixerunt: Propone quod disponis. Cyrila dixit: Nescio latine. Nostri episcopi dixerunt: Semper te latine esse locutum manifesto novimus; modo excusare non debes, praesertim quia tu huius rei incendium suscitasti. Vgl. Vössıng, 'Barbaren' und Katholiken (wie Anm. 33) S. 202 und Anm. 127. Ich danke Konrad Vössing (Bonn) für seine Hilfe bei der Übersetzung! 


\section{Die vandalischen Königstitel und ihre Implikationen für das Herrschaftsverständnis der Könige in Karthago}

Die Selbstdefinition der vandalischen Könige ist illustrierbar mit einer Formulierung im ersten bei Victor von Vita überlieferten Mandat Hunerichs, in dem von Gott gegebenen Herrschaftsansprüchen die Rede ist: In provinciis a Deo nobis concessis scandalum esse nolumus. ${ }^{39}$ Die Autorität des Königs Hunerich kommt in dem 478 erlassenen Edikt zur Autorisierung der Wahl des Eugenius zum Bischof von Karthago zum Ausdruck: Iussit vobis domnus dici. Noch deutlicher wird dieser Machtanspruch im vom nämlichen König erlassenen Verbot katholischer Kulte in bestimmten Gebieten, den sortes Vandalorum: Rex Hunirix Wandalorum et Alanorum universis populis nostro regno subiectis. Yves Modéran hat diese in der Forschung so hervorgehobene und auf Vandalen und Alanen beschränkte Titulatur als Versuch einer ethnischen und religiösen Trennung zwischen Eroberern (,Germanen' und Alanen) und Besiegten (Römern) gedeutet. Der Machtanspruch beziehe sich auf alle Bewohner der Provinzen, ohne die Römer in der Titulatur zu nennen. Im Gegensatz dazu kenne man den Titel des maurischen Königs Masuna am Beginn des 6. Jahrhunderts, der sehr wohl die Römer einschließt. ${ }^{40}$

Die neue militärische und politische Elite wird im (lateinischen) Herrschertitel genannt. Ob damit bewusst eine Rangordnung, die die Römer schlechter stellte, gemeint war, ist zu bezweifeln, auch wenn im vandalischen Nordafrika die Konflikte um Besitzzuteilungen aggressiver ausgetragen worden waren als etwa im ostgotischen Italien, wo Liberius mit diesen Vorgängen betraut war und es offenbar schaffte, weitgehend ohne harsche Auseinandersetzungen zu agieren. Weiters steht zu bedenken, dass der Königstitel Rex Vandalorum et Alanorum lediglich in zwei von der Diplomatik als relativ authentisch definierten Mandaten nach dem Vorbild kaiserlicher Edikte bei Victor und auf einer Silberschale

39 Vict. Vit. (wie Anm. 4) 2, 39.

40 Vict. Vit. (wie Anm. 4) 2, 3; 2, 39; Corpus Inscriptionum Latinorum VIII, Berlin 1891, 9835 und Jean Marcillet-Jaubert, Les inscriptions d'Altava (Publications des annales de la Faculté des Lettres Aix-en-Provence N.S. 65) Paris 1968, S. 126-127, No. und Abb. 194: pro sa(lute) et incol(umitate) reg(is) Masunae gent(ium) Maur(oru)m et Romanor(um). Vgl.Yves Modéran, L'établissement territorial des Vandales en Afrique, in: Antiquité Tardive 10 (2002) S. 87 - 122, hier S. 95. Ähnlich argumentiert Vössıng, ,Barbaren` und Katholiken (wie Anm. 33) S. 180. Vgl. weiter Jérôme CARCopino, Un ,empereur' maure inconnu d'après une inscription latine récemment découverte dans l'Aurès, in: Revue d'Ėtudes Anciennes 46 (1944) S. 94 - 120; Herwig Wolfram, Intitulatio I. Lateinische Königs- und Fürstentitel bis zum Ende des 8. Jahrhunderts (Mitteilungen des Insituts für Österreichische Geschichtsforschung Erg. Bd. 21) Graz 1967, S. 82 - 84 deutet den Masunatitel als eine Imitation des vandalischen: „Die Römer werden zu einer gens wie jede andere.“ 
Gelimers in dieser Form belegt ist. ${ }^{41}$ Denkt man daran, dass 476 das westliche Kaisertum zu Ende ging, fällt auf, dass neue politische Terminologie in der Regel nach dem Tode Geiserichs $477 \mathrm{zu}$ datieren ist. Nach der Absetzung des Romulus konnte man auch noch andere bisherige kaiserliche Reservatrechte beanspruchen und so ließ Hunerich Hadrumetum (Sousse) in Huniricopolis umbenennen. ${ }^{42}$

Neben dem aus den Mandaten bei Victor bekannten Titeln, die die ethnischen Labels ,Vandalen' und ,Alanen' verwenden, finden sich aber noch eine ganze Reihe anderer königlicher Sprachregelungen. Auf einem der Tablettes Albertini, gut erhaltenen, auf Holztäfelchen geschriebenen Verträgen und Rechnungen aus der Regierungszeit Gunthamunds, erscheint die Titulatur rex invictissimus. ${ }^{43}$ In den Akten des Konzils von 525 in Karthago wird mit anno secundo gloriosissisimi regis Hilderici datiert. Fulgentius von Ruspe, der die Gelegenheit ergriff, das katholische Dogma König Thrasamund darzulegen, spricht den König mit rex clementissimus oder piissimus an. Victor von Vita bringt bei seinem Zitat des Edikts König Hunerichs die Ausdrücke clementia nostra oder pietas nostra als Selbstbezeichnung des vandalischen Herrschers. ${ }^{44}$ Die Attribute invictissimus, gloriosissisimus, clementissimus und piissimus sind auffallend. Solche Terminologie kennen wir sonst in der Anrede des römischen Kaisers, der als imperator oder princeps angesprochen wurde. $\mathrm{Zu}$ dieser Titulatur traten die Attribute $p i$ issimus, clementissimus, sapientissimus oder eben invictissimus. ${ }^{45}$

Die Invictie, die Unbesiegtheit der Feldherren war ein besonderes Prädikat.

41 Wolfram, Intitulatio I. (wie Anm. 40) S. 79-87; Richard Heuberger, Vandalische Reichskanzlei und Königsurkunde im Vergleich mit verwandten Einrichtungen und Erscheinungen, in: Festschrift Oswald Redlich zum 70. Geburtstag, hg. von Wilhelm BAUER (Mitteilungen des Instituts für Österreichische Geschichtsforschung Erg. Bd. 11) Innsbruck 1929, S. 76 - 113; Wolfram, Goten (wie Anm. 27) S. 295-299; Walter Pohl, Die Völkerwanderung. Eroberung und Integration, Stuttgart 2002, S. 137.

42 Michael McCormick, The origins of the European economy. Communications and Commerce c.700-c.900, Cambridge 2001, S. 262; Courtors, Les Vandales (wie Anm. 5) S. 345 347.

43 Tablettes Albertini I, 1: [ann] nono d(omi)n(i) invictissimi regis XV k(a)l(endas) octob(res) tab(ella)... ed. und vgl. Christian Courtois - Louis Leschi - Charles Perrat - Charles Saumagne, Tablettes Albertini. Actes privés de l'epoque vandale (Fin du $\mathrm{V}^{\mathrm{e}}$ siècle) Paris 1952, S. 215 und die Liste zur „Titulature royale“ S. 315. In allen anderen Tablettes erscheint domini (nostri) regis mit verschiedenen Schreibweisen des Namens Gunthamund. Nur in I, 1 findet sich invictissimi regis.

44 Fulgentius von Ruspe, Ad Trasimundum regem Vandalorum libri tres 1, 1 und 2, ed. JeanPaul Migne (PL 65) Paris 1847, S. 223-302; Vict. Vit. (wie Anm. 4) 3, 3 und 12 ; Vgl. ModÉRAN, L'établissement territorial des Vandales (wie Anm. 40) S. 96 mit Anm. 61-63.

45 Cassiodorus, Variae 10, 19, 3 (Theodahad an Justinian piissime); 1, 1, 1 (Theoderich an Anastasios clementissime); 10, 9, 1; 1, 1, 2 und 5; 8, 1, 1; 10, 1, 1 (Athalarich und Amalaswintha an Justinus I. und Justinian clementissime principum), ed. Theodor Mommsen (MGH AA 11, CM 2) Berlin ${ }^{2}$ 1981, S. 109-162. 
Commodus ließ sich darüber hinaus als Hercules Romanus stilisieren. Weiters findet sich das Epitheton im Umfeld des Mithraskults. Im Osten begegnet die

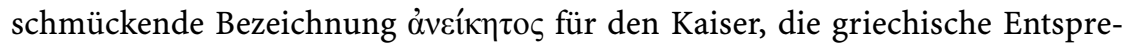
chung des lateinischen invictus, die seit Trajan belegt ist. Allerdings fehlt das Epitheton in der offiziellen Titulatur, so kommt es etwa nicht in Militärdiplomen

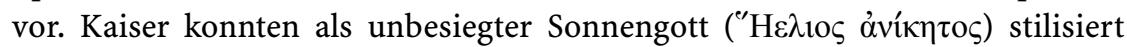
werden. Seit Septimius Severus und bis Konstantin I. findet sich diese Variante. Der Kaiser wird der unbesiegten Sonne als sol invictus/helios aniketos gleichgesetzt. Er geht aus dem Kampf mit den Mächten der Finsternis siegreich hervor. Leo Berlinger bezeichnete den Kaiser in diesem Zusammenhang als einen „fleischgewordenen obersten Gestirngott“. Nach Kaiser Julian findet sich invictus nur noch in der Panegyrik. ${ }^{46}$ Solche Terminologie steht deutlich über der Verwendung von Ehrenprädikaten der ersten senatorischen Rangklasse wie excellentissimus, praecellentissimus, excelsus und magnificus für Mitglieder des gotischen Herrscherhauses in Italien und später die fränkischen wie auch langobardischen Könige. ${ }^{47}$

Ein rex aus barbarisch-militärischem Milieu konnte allerdings erst nach der Konversion zum Katholizismus zu einem rex christianissimus werden. Dies blieb den westgotischen Herrschern für die Zeit nach 589 vorbehalten. Eine gewollte Analogie mit der kaiserlichen Position findet sich in der Satisfactio ad Gunthamundum regem des Blossius Aemilius Dracontius. Gunthamund wird mit Caesar, Augustus und Titus verglichen, die berühmt für ihre Gnade seien. ${ }^{48}$

46 Мах Iмноғ, „invictus“, in: Thesaurus Linguae Latinae, Bd. 7, 2, Leipzig 1904, Sp. 185 -190; Leo Berlinger, Beiträge zur inoffiziellen Titulatur der römischen Kaiser. Eine Untersuchung ihres ideengeschichtlichen Gehaltes und ihrer Entwicklung, Breslau 1935, S. 22. Max IMHOF, Invictus. Beiträge aus der Thesaurusarbeit X, in: Museum Helveticum 14 (1957) S. 197-215; C. T. H. R. EhrhardT, „Maximus“, „invictus“ und „victor“ als Datierungskriterien auf Inschriften Konstantins des Grossen, in: Zeitschrift für Papyrologie und Epigraphik 38 (1980) S. 177-181; Stephan Berrens, Sonnenkult und Kaisertum von den Severern bis zu Constantin I. 193 - 337 n. Chr. (Historia Einzelschriften 185) Stuttgart 2004, S. $205-242$.

47 Epistulae Theodericianae Variae 4, 5, 8, ed. Theodor Mommsen (MGH AA 12) München ${ }^{2}$ 1981; Cassiod. var. 10, 2, 1: Theodahad läßt Justinian als piissime imperator ansprechen und nennt Amalaswintha praecellentissima domna. Epist. Thiel 12 p. 266: Kaiser Anastasios bezeichnet Theoderich als gloriosissimus rex und Hormisdas als beatissimus papa. Rudolf Helm, Untersuchungen über den auswärtigen diplomatischen Verkehr des römischen Reiches im Zeitalter der Spätantike, in: Archiv für Urkundenforschung 12 (1932) S. 375 -436, hier S. 384-386 mit weiteren Beispielen in den dortigen Anm. Die S. 384, Anm. 11 behauptete Bezeichnung Theoderichs als invictissimus durch Justinian (der 518 noch comes war) im Brief Epist. Thiel 44 p. 833 bezieht sich auf Kaiser Justinus: Dominus etenim noster invictissimus imperator (...). Ein prägnanter Überblick zu senatorischen Titeln: DEMANDT, Die Spätantike (wie Anm 3) S. 335 f.; Vössıng, 'Barbaren' und Katholiken (wie Anm. 33) S. $189-191$.

48 Blossius Aemilius Dracontius, Satisfactio, ed. Claude Moussy, Euvres de Dracontius 2 
Einen weiteren scheinbar geläufigen vandalischen Königstitel gilt es in einen wenig spektakulären römischen Kontext zurückzuordnen; jenen des „Königs des Landes und des Meeres“. Bereits Conrad Mannert nahm Ende des 18. Jahrhunderts an, Geiserich habe nach der Eroberung Karthagos den Titel „Landund Wasserkönig“ angenommen. Im 19. Jahrhundert schrieb Felix Dahn Geiserich den Titel eines „Meerkönigs“ $z u .{ }^{49}$ Diese scheinbare Titulatur geht auf den im 8. Jahrhundert, gestützt auf Prokop und Priskos, schreibenden byzantinischen Autor Theophanes zurück: „Im selben Jahr wurde Geiserich bei der Vandalenschar mächtig. Er nannte sich rex. Er nahm Land, Meer und viele Inseln, die den Römern tributpflichtig gewesen waren, in Besitz. Das bekümmerte den Theodosius. “50

Geiserich wurde König, mehr hat Theophanes nicht gesagt. In genannter Stelle bleibt die Bezeichnung, von Titulatur kann kaum gesprochen werden, des Vandalenkönigs eine gräzisierte Form von rex. Die Konstruktion eines dergestaltigen Titels ist eine der modernen Forschung.

In der römischen Literatur und Epigraphik gibt es allerdings Analogien zu einer solchen Terminologie, die Macht und Herrschaft auf Land und Meer zusammen beziehen wollte. Indirekt liegt bei Theophanes sehr wohl ein Bezug zur antiken Herrscherakklamation vor, allerdings ein polemischer. Römische Kaiser konnten als „Herrscher des Landes und des Meeres“ bezeichnet werden. Wir kennen inschriftliche Belege, die eine vergleichbare Anrede für Aurelian als „Herrscher der Erde, des Meeres und der ganzen Oikumene“ (ó $\gamma \eta \hat{\varsigma} \varsigma \kappa \alpha i ̀ ~ \theta \alpha \lambda \alpha ́ \sigma-$

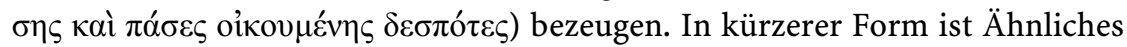

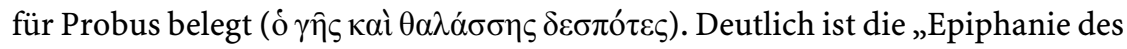

(Collection des Universités de France) Paris 1988; vgl. Andrew H. Merrills, The Perils of Panegyric: The Lost Poem of Dracontius and its Consequences, in: Vandals, Romans and Berbers. New Perspectives on Late Antique North Africa, hg. von Andrew H. Merrills, Aldershot 2004, S. $145-162$.

49 Mannert, Geschichte der Vandalen (wie Anm. 10) S. 60-61; Felix Dahn, Genserich, in: Allgemeine Deutsche Biographie Bd. 8 (1878) Sp. 569-573: „See- oder Meerkönig“; SснміDт, Geschichte der Wandalen (wie Anm. 8) S. 96: „Es klingt überspannt, wenn er sich, wie Theophanes angibt, König des Landes und des des Meeres genannt hat." Für den Titel: Felix Papencordt, Geschichte der vandalischen Herrschaft in Afrika, Berlin 1837, S. 75; Franz Miltner, Vandalen, in: Realencyclopädie Bd. 8, 1 A (1955) Sp. 298-335, hier 317; Helmut Castritius, Wandalen $\$ 1$, in: Reallexikon der Germanischen Altertumskunde Bd. 33 (2006) Sp. 168-209, hier Sp. 198; Guido M. Berndt - Philipp von RummeL - Roland Steinacher, Rezension zu: The true story of the Vandals. Museum Vandalorum Värnamo, Eigenverlag, Värnamo 2001, in: Zeitschrift für Archäologie des Mittelalters 34 (2006) S. 313 316, hier S. 314.

50 Theophanes Confessor, Chronographia a. m. 5941, ed. Karl DE Boor (CSHB) Hildesheim -

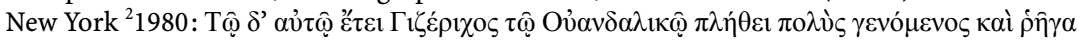

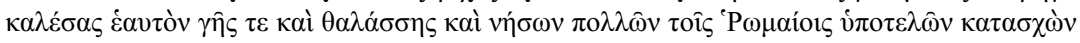

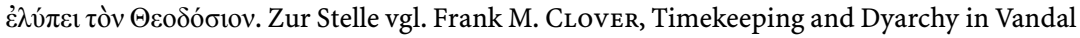
Africa, in: Antiquité Tardive 11 (2003) S. 45-63, hier S. 59-61. 
Gottes der Erde und des Meeres“, Vespasian. Schließlich bringt Ammianus Marcellinus einen Brief des Constantius I. an den Perserkönig Sapor, der in der Einleitung den römischen Kaiser als Victor terra marique Constantius bezeichnet. $^{51}$

Wahrscheinlich zu machen ist nun, dass Theophanes oder seine Quelle Priskos, der mit der Übernahme lateinischer Worte manchmal seine Bildung zeigte, das Wort rex gebrauchte und die Wortwahl eine Platzanweisung für einen Barbarenkönig darstellt. Der wesentliche Gedanke stammt von Christoph Markschies. Theophanes setzt den Vandalenkönig erneut - ähnlich wie Victor von Vita - in eine Beziehung zu heidnischen Kaisern. Der Vandalenkönig wird zwar nicht direkt wie Aurelian oder Vespasian tituliert, einem gebildeten Leser wird die Analogie aber klar gewesen sein. ${ }^{52}$

Nun bleibt aber die bei Theophanes so oft als direkte Titulatur missverstandene Erwähnung Geiserichs immer noch maximal eine Anspielung. Eine mögliche ikonographische Parallele in der ein barbarischer König mit dem Machtattribut der Herrschaft über Land und Meer in Verbindung gebracht wird und damit zum Fall Geiserichs, könnte ein nur aus einer Beschreibung des 9. Jahrhunderts bekanntes Mosaik in Ravenna gewesen sein. Ein von Agnellus in seiner Bistumsgeschichte Ravennas (Liber Pontificalis) beschriebenes Mosaik im Frontkomplex des Palastes Theoderichs dürfte eine gänzlich unpolemische ikonographische Analogie zur römischen Akklamation der vergöttlichten Kaiser darstellen. Im Giebel des Hauptportals soll der Gotenkönig zu Pferd gepanzert mit Schild und Lanze dargestellt gewesen sein. Links und rechts sah man Personifikationen der Städte Rom und Ravenna. Daneben findet sich bei Agnellus die Erwähnung eines weiteren Mosaiks in der Apsis des im Bereich des Palastes gelegenen triclinium ad mare. Die Rede ist in diesem Zusammenhang

51 Ammianus Marcellinus, Res Gestae 17, 6, 10, ed. Wolfgang Sey farth, Ammiani Marcellini Rervm gestarvm libri qvi svpersvnt (Bibliotheca scriptorvm Graecorvm et Romanorvm Tevbneriana) Leipzig 1978; Bülent İpLİKçİoĞLU, Zwei Statthalter vespasianischer Zeit und die „Große“ Therme in Inschriften von Olympos (Lykien), in: Anzeiger der Phil.-Hist. Klasse der Österreichischen Akademie der Wissenschaften 141 (2006) S. 75 -81, hier S. 75 f., S. 80

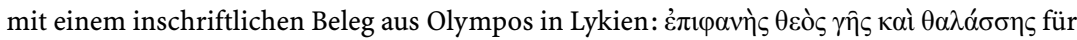
Vespasian. Vgl. Helm, Untersuchungen (wie Anm. 47) S. 378 mit Anm. 3; Wolfram, Intitulatio I. (wie Anm. 40) S. 84 und Anm. 43: „Die Titulatur Geiserichs steht jedoch (...) in der Tradition der antiken Herrscherakklamation. Darum muß Geiserichs literarisch überlieferte Appellation nicht falsch sein; aber sie ist keine Selbstaussage. "Ludwig SснміDт, Geschichte der deutschen Stämme bis zum Ausgang der Völkerwanderung. Die Ostgermanen, München 1934 - 1941, S. 113, Anm. 1.

52 Christoph Markschies, The Religion of the Late Antiquity Vandals: Arianism or Catholicism?, in: The true story of the Vandals. Museum Vandalorum Värnamo, ed. Pontus Hultén, Värnamo 2001, S. 88-97, hier S. 93 mit Domitian und seiner in christlichen Augen untragbaren Titulatur als Dominus ac Deus, auf die in der Apokalypse des Johannes angespielt wird. Vgl. Clover, Timekeeping (wie Anm. 51) S. 60. 
von einer weiteren Bilddarstellung des Königs zu Pferd. Auf dieser hat nun der patricius Theoderich ein Bein über dem Meer, ein anderes über dem Land. ${ }^{53}$

\section{Eine vandalische ,Tracht' als Kleidung bei Hof ? Anmerkungen zu Victors „habitus barbarus“ und der These von ,Romanen“ versus ,Germanen` als Hintergrund der Konflikte im spätantiken Nordafrika}

Eine weitere Episode bei Victor von Vita beschreibt einen Konflikt am Hof des Vandalenkönigs. Kleidung wird als Distinktionsmerkmal namhaft gemacht. An der Kleidung seien die am Hof tätigen Personen erkennbar gewesen, so Victor. Die Stelle wurde viel diskutiert, vor allem in der Archäologie. Am Hof und in der Verwaltung tätige Afrikaner wechselten unter einem gewissen Druck, aber sicherlich in vielen Fällen auch karriereorientiert freiwillig, zum homöischen Bekenntnis, um vom König anerkannt zu werden. Am Höhepunkt der Konflikte zwischen Homöern und Katholiken in der Regierungszeit Hunerichs ist von der Aufforderung der arianischen Bischöfe an den katholischen Bischof Eugenius die Rede, allen nach barbarischer Art gekleideten Menschen (in habitu barbaro) den Eintritt in die katholischen Kirchen zu verbieten. Der Bischof von Karthago lehnte dies ab, denn viele seiner Katholiken seien bei Hof tätig und auch entsprechend gekleidet (in habitu illorum). Außerdem könne ein Bischof den Gläubigen nicht den Trost des Glaubens verwehren. Als Reaktion auf diese Weigerung soll der König Bewaffnete - Victor spricht von tortores - vor den katholischen Kirchen Karthagos postiert haben und die durch ihre Kleidung identifizierbaren Frauen und Männer wurden angehalten. (Qui videntes feminam vel masculum in specie suae gentis ambulantes). Die Wachen setzten mit Zacken bewehrte Stäbe an den Haaren an und rollten das Haupthaar gänzlich auf. Daraufhin zogen die vandalischen Folterer kräftig an und skalpierten die Betroffenen. Manche der so Gemarterten sollen ihr Augenlicht verloren haben, andere wegen der grauenhaften Schmerzen gleich gestorben sein. Von den

53 Agnell. Rav. Lib. Pont. Rav. 94, ed. Deborah Mauskopf-Deliyannis, Agnelli Ravennatis Liber Pontificalis Ecclesiae Ravennatis (Corpus Christianorum Continuatio Medievalis 199) Turnhout 2006, S. 258-259: Unde vero telum tenensque fuit, Ravenna tessellis figurata, pedem dextrum super mare, sinistrum super terram ad regem properans. Vgl. Andreas Goltz, Barbar - König - Tyrann. Das Bild Theoderichs des Großen in der Überlieferung des 5. bis 9. Jahrhunderts (Millennium-Studien zu Kultur und Geschichte des ersten Jahrtausends n. Chr. 12) Berlin - New York 2008, S. 533-534; Friedrich W. Deichmann, Ravenna, Hauptstadt des spätantiken Abendlandes 1. Geschichte und Monumente, Wiesbaden 1969, S. 120; Ders., Ravenna, Hauptstadt des spätantiken Abendlandes 2, 3. Kommentar. Geschichte, Topographie, Kunst und Kultur, Stuttgart 1989, S. $51-53$ und S. 74-75. 
skalpierten Frauen wird noch gesagt, sie seien mit ihren kahlen Köpfen durch die Straßen Karthagos getrieben worden. Vor ihnen zogen Ausrufer, um die ganze Stadt auf die Unglücklichen und ihre Schande aufmerksam zu machen. ${ }^{54}$ Weil all dies nichts nutzte, der Wall des Glaubens nicht einzureißen war, wurde den Hofbediensteten das Gehalt gestrichen. (At ubi isto modo fidei infringere non valuit murum, cogitat ut nostrae religionis homines in aula eius constituti neque annonas neque stipendia solita potirentur.) Als nächste Konsequenz verurteilte Hunerich frei geborene und körperlich wenig belastbare Männer - viros ingenuos et admodum delicatos - zu harter körperlicher Arbeit auf königlichen Gütern. ${ }^{55}$

Obwohl Victor nur von einer Kleidung, die auch Katholiken, unter diesen sicherlich viele Römer, getragen haben, spricht (multitudo nostrorum catholicorum in habitu illorum), wurde und wird diese Quellenstelle immer wieder als Beleg für eine ,vandalische Stammestracht' zitiert. $^{56}$ Jüngere Interpretationen, wie jene Philipps von Rummel, wollen nun in Victors barbarischem Habitus eine, in einen spätantik-mediterranen Kontext einzuordnende, höfisch-repräsentative Kleidung sehen, die die Zugehörigkeit zur Führungsschicht bzw. dem Hof ausdrücken sollte und nicht etwa eine Verbundenheit mit alten Traditionen aus Gegenden nördlich des Mittelmeers. „Victors habitus barbarus hatte wohl nichts wirklich Barbarisches oder Fremdes an sich, sondern war schlichtweg die Kleidung der Führungselite des vandalischen Afrika, jener Gruppe, die man unabhängig von ihrer Kleidung und Religion als Vandalen bezeichnen kann. ${ }^{\text {" }} 7$

Wie soll man sich eine vandalische Kleidung nun aber vorstellen, wie wären die am Konflikt bei Hof beteiligten Vandalen also von den Römern abgrenzbar gewesen und wie soll man Victors Geschichte und Terminologie verstehen? Die

54 Vict. Vit. (wie Anm. 4) 2, 8 und 9; vgl. Philipp von Rummel, Les Vandales ont-ils porté en Afrique un vêtement spécifique?, in: La Méditerranée et le monde mérovingien: témoins archéologiques. Actes des XXIIIe Journées internationales d'archéologie mérovingienne, Arles 2003 (Bulletin Archéologique de Provence Suppl. 3) hg. von Xavier Delestre - Patrick PÉRIN - Michel Kazanski, Aix-en-Provence 2005, S. 281 -291, hier S. 282.

55 Vict. Vit. (wie Anm. 4) 2, 9; vgl. Howe, Vandalen, Barbaren und Arianer (wie Anm. 9) S. 163 - 164 und Anm. 26. Ich danke Konrad Vössing (Bonn) für seine Hilfe bei der Übersetzung!

56 Volker Bierbrauer, Wandalen $\$ 2$, in: Reallexikon der Germanischen Altertumskunde Bd. 33 (2006) Sp. 214 -215; Spielvogel, Arianische Vandalen (wie Anm. 23) S. 206 nimmt an, die Vandalen hätten die Römer gezwungen, sich deren Tracht anzuziehen. In der $\mathrm{Zu}$ sammenfassung S. 221 meint er dann gar: „Über eine vandalische Kleiderordnung wurde der Königshof auch äußerlich gleichgeschaltet (...)“. Dieser Gedanke findet sich bereits bei SснмidT, Geschichte der Wandalen (wie Anm. 8) S. 150 und Anm. 2, der noch eine Analogie zu den Langobarden herstellt. Diese hätten italienische Stadtbürger zum Tragen langer Haare gezwungen. Ähnlich auch Courtors, Les Vandales (wie Anm. 5) S. 252 mit Anm. 8.

57 Philipp von Rummel, Habitus barbarus. Kleidung und Repräsentation spätantiker Eliten im 4. und 5. Jahrhundert (RGA Erg. Bd. 55) Berlin - New York 2007, S. 191. 
frühgeschichtliche Archäologie hat sich in den letzten beiden Jahrhunderten darum bemüht, das spezifisch ,Germanische' der Vandalen in Nordafrika zu isolieren und zu typologisieren. Da es wenige Quellen gibt, die eine vandalische Sicht der Dinge beinhalteten, spielte die Archäologie bei den Versuchen, die Frage, wie das vandalische, Volk', nach dem man in der Denktradition Herders als kollektive Individualität suchte, denn zu beschreiben sei, immer eine große Rolle. Im Folgenden sollen die schon von Christian Courtois als Nachweis vandalischer Präsenz gesehenen Gräber und einige Mosaikdarstellungen besprochen werden..$^{58} \mathrm{An}$ unseren Vorstellungen von sich gegenüberstehenden und scheinbar klar definierbaren ,germanischen' und ,romanischen 'Gruppen in der Spätantike und dem frühen Mittelalter entzünden sich jedenfalls zusehends Diskussionen. ${ }^{59}$

Die ältere archäologische Forschung suchte nach einer, gruppenspezifischen ${ }^{`}$ Kleidung der Vandalen im Sinn einer Stammestracht. Nicht ganz drei Dutzend Gräber mit Schmuck und Kleidungsteilen stehen im Mittelpunkt dieser Frage. Gerd König typisierte 1981 noch alle Bestattungen mit Beigaben auf afrikanischem Boden als ,vandalisch'. Einfibeltracht, Gürtel und Schuhgarnitur wurden von König als Kennzeichen des vandalischen Männergrabes genannt. ${ }^{60}$ Dieses Inventar kommt aber vollständig nur bei einem einzigen Grab in Thuburbo Maius vor, bei dem ein Grabmosaik mit dem Namen Arifridos gefunden wurde. ${ }^{61}$ Mittlerweile beschränkt sich die Diskussion auf nur mehr sieben nordafrikanische Grabfunde, „die wegen ihrer besonderen, vom gleichzeitigen einheimisch-romanischen Bestattungsbrauch abweichenden Ausstattung mit Kleidungszubehör und Schmuck als vandalisch anzusehen seien. ${ }^{\text {“62 }}$ Dabei handelt es

58 Courtois, Les Vandales (wie Anm. 5) S. 178. Die Frage der ethnischen Deutbarkeit archäologischer Funde behandelt Sebastian BRATHER, Ethnische Interpretationen in der frühgeschichtlichen Archäologie. Geschichte, Grundlagen und Alternativen (Reallexikon der Germanischen Altertumskunde Erg. Bd. 42) Berlin - New York 2004. Gegen diese grundlegende Arbeit Brathers: Volker Bierbrauer, Zur ethnischen Interpretation in der frühgeschichtlichen Archäologie, in: Die Suche nach den Ursprüngen. Von der Bedeutung des frühen Mittelalters (Österr. Akademie der Wissenschaften, Denkschriften der phil.-hist. Klasse 322, Forschungen zur Geschichte des Mittelalters 8) hg. von Walter PoHL, Wien 2004, S. $45-84$.

59 Vgl. zur problematischen Begrifflichkeit des ,Romanischen' Hubert FeHR, RomanischGermanische Sprachgrenze, in: Reallexikon der Germanischen Altertumskund Bd. 25 (2003) Sp. 304-310 mit dekonstruktivistischen Ansätzen und Volker BierbraUer, Romanen, in: Reallexikon der Germanischen Altertumskunde Bd. 25 (2003) Sp. 210-242 mit einer Position, die ethnische Zuweisungen auf der Basis typologischer Überlegungen vornimmt.

60 Gerd G. KöNIG, Wandalische Grabfunde des 5. und 6. Jahrhunderts, in: Madrider Mitteilungen 22 (1981) S. 299-360, hier S. 300.

61 Dieter QuAST, Völkerwanderungszeitliche Frauengräber aus Hippo Regius (Annaba - Bône) in Algerien, in: Jahrbuch des Römisch-Germanischen Zentralmuseums Mainz 52 (2005) S. 237-315, hier S. 273-275.

62 Christoph Eger, Vandalisches Trachtzubehör? Zu Herkunft, Verbreitung und Kontext aus- 
sich um drei Gräber aus der Umgebung von Hippo Regius, die reich ausgestatteten Frauengräber von Koudiat Zâteur und Douar-ech-Chott bei Karthago und ein Frauengrab wie das Arifridos- Grab aus der sogenannten Tempelkirche von Thuburbo Maius. ${ }^{63}$

Um die Mitte des fünften Jahrhunderts wurde ein reicher Mann mit dem Namen Arifridos in der genannten Kirche in Thuburbo Maius (Henchir Kasbat) bestattet, an einem prominenten Platz also. Nur insgesamt fünf Gräber wurden bei den Ausgrabungen in der Kirche gefunden. Am Ende des rechten Seitenschiffs der Kirche, die auf dem Gelände des Tempels der Gottheiten Baal und Tanit errichtet worden war, wurde das Grab 1920 entdeckt. Die zugehörige Inschrift kannte man schon ein Jahr zuvor. Nicht ganz einen Meter unter dem Grabmosaik mit der verstümmelten Inschrift, dass hier Arifridos liege, der in Frieden ruhen solle, befand sich eine Grabkammer aus Kalksteinplatten. In der Kammer lagen Holzreste und elf Nägel, wahrscheinlich die Überreste eines Sarges. Weiters fanden sich eine Ovalscheibenfibel mit einem gefassten Sardonyx und einer Randverzierung aus Perldraht wie zwei Schuhschnallen mit ovalen Goldbeschlagkästen und mugeligem gefasstem Granat. Die Ausstattung des Arifridos umfasste noch eine weitere Schnalle aus Bronze mit einem ähnlich gearbeiteten ovalen Beschlag, dessen Einlage allerdings verloren ging. ${ }^{64}$ Hierbei handelt es sich um einen mediterranen, schon aus spätrömischer Zeit bekannten Fibeltyp, der dem vornehmen Vandalen Arifridos als Mantelverschluss diente. „Wie aber wäre das Grab ohne entsprechende Grabinschrift gedeutet worden? Für einige wäre es vielleicht ein Germane, für andere vielleicht ein Römer geworden. So zeigt sich, dass die Aufgabe, über die ethnische Zugehörigkeit des

gewählter Fibeltypen in Nordafrika, in: Das Reich der Vandalen, hg. von BERNDT - STEINACHER (wie Anm. 2) S. 183 - 196, hier S. 184.

63 Christoph EgER, Vandalische Grabfunde aus Karthago, in: Germania 79/2 (2001) S. 347 390; Ders., Koudiat Zâteur, in: RGA 2. Aufl. Bd. 17 (2001) Sp. 267 -269; Ders., Vandalisches Trachtzubehör? (wie Anm. 62) S. 183 - 196; Jörg KleEmanN, Quelques réflexions sur l'interprétation ethnique des sépultures habillées considérées comme Vandales, in: Antiquité Tardive 10 (2002) S. 123 - 129.

64 Philipp von Rummel, Where have all the Vandals gone? Migration, Ansiedlung und Identität der Vandalen im Spiegel archäologischer Quellen aus Nordafrika, in: Das Reich der Vandalen, hg. von Berndt - Steinacher (wie Anm. 2) S. 149-182, hier S. 158-159 und Anm. 63 mit Literaturangaben; Ders., Habitus barbarus (wie Anm. 57) S. 337-342 mit einer Diskussion des Forschungsstands; DeRs., Habitus Vandalorum? Zur Frage nach einer gruppenspezifischen Kleidung der Vandalen in Nordafrika, in: Antiquité Tardive 10 (2002) S. 131 - 141, hier S. 135-136; Christoph EgER, Silbergeschirr und goldene Fibeln. Die vandalische Oberschicht im Spiegel der Schatz- und Grabfunde in Nordafrika, in: Antike Welt 35 (2004) S. 71-76, hier S. 76 und Abb. 12; KöNIG, Wandalische Grabfunde (wie Anm. 60) S. $310-312$, S. 324 und Abb. 11, Tafel 48c; Kleemann, Quelques réflexions (wie Anm. 63). S. 125 - 126, Abb. 1; zum Namen vgl. Courtors, Les Vandales (wie Anm. 5) S. 382, Nr. 127: ARIFRIDOS IN P[ACE] VIXIT ANNOS [...] DEPOSITUS DIE [...] IDUS NOVEMB[RES]; vgl. Francovich Onesti, I Vandali (wie Anm. 21) S. 148. 
Arifridos anhand der wenigen Reste seiner Kleidung zu entscheiden, eine sehr heikle ist. "65

1912 fanden französische Archäologen im Atrium vor dem Eingang derselben Kirche in Thuburbo, in der Verlängerung der Hauptachse, ein reiches Frauengrab. Auch die Basen eines Grabmonuments gehörten dazu. $150 \mathrm{~cm}$ tief lag eine Grabkammer, wieder aus Kalksteinplatten. Die West-Ost Bestattung mit Resten eines Holzsargs ähnelt also der des Arifridos. Zwei kleine goldene Armbrustfibeln lagen im Grab, vor allem aber ein Collier aus 23 zweiseitig getreppten, gleichseitigen Dreiecken aus Goldblech. Auf der Rückseite fanden sich jeweils zwei kleine Röhrchen aufgelötet, eines oben und eines unten, so dass sie doppelt aufgezogen werden könnten. Weiters gehörten zwei Goldohrringe mit Schmucksteinanhängern und ovalen Amethystperlen zur Ausstattung des Frauengrabs. ${ }^{66}$

Arifridos war ein reicher und mächtiger Mann, denn im rechten Seitenschiff der Kirche der Stadt bestattet zu werden war ein großes Privileg weniger römischer Christen. Auch die Erinnerung an eine Person durch ein teures Grabmosaik war einer Elite vorbehalten. Seine Kleidung, die Fibel und die Schuhschnallen gehörten zur schicken Mode der spätrömischen Oberschicht mit Anspielungen auf die Kleidung der Militärs. Dies nicht etwa deshalb weil Arifridos vielleicht ein Vandale war, man trug im spätantiken Mittelmeerraum eben ,military look', wenn man etwas auf sich hielt. Andrew H. Merrills hat dies auf den Punkt gebracht: „Arifridos was a Vandal who dressed very much like a late Roman dandy." Die in der gleichen Kirche bestattete Dame hatte auch den typischen Schmuck der spätrömischen Aristokratie im Grab. Wir wissen ihren Namen nicht, aber es sei mit der jüngst erschienen Vandalengeschichte von Merrills und dem Archäologen Richard Miles erlaubt, einige Fragen zu stellen, um die Probleme anzudeuten, die wir bei der Deutung der Quellen haben. Was wenn die beiden verheiratet gewesen wären? Wenn Arifridos ein Vandale und mit dieser Frau schon in Spanien verheiratet gewesen wäre, was sagte dies über ihre Identität oder Selbstdefinition aus? Was änderte sich, wenn die Frau einfach ein Mädchen aus Thuburbo gewesen wäre und den feschen jungen Offizier geheiratet hätte, der nach 439 in die Stadt kam? Oder wenn Arifridos doch kein Vandale gewesen wäre und ihm sein Vater aus einer Laune oder aus Opportunismus einen Modenamen gegeben hätte, um den neuen Herren zu gefallen oder weil es einfach schick war und die Dame eine Eingewanderte? Oder wenn keiner von Beiden sich jemals als Vandalin oder Vandale gesehen hätte und die Gräber

65 Von Rummel, Habitus barbarus (wie Anm. 57) S. 340; Ders., Les Vandales ont-ils porté en Afrique un vêtement spécifique? (wie Anm. 54) S. 285-287.

66 KönIg, Wandalische Grabfunde (wie Anm. 60) S. 310-312 mit Abb. 6a-c; Eger, Vandalisches Trachtzubehör? (wie Anm. 62) S. 187 f. 
einfach aus Gründen, die wir nicht kennen, die beigabenführende Ausnahme darstellten? Wir wissen all dies nicht und die scheinbaren Sicherheiten der älteren Forschung sind uns ob vieler Vergleiche und schärferen Nachdenkens abhanden gekommen. Wir können nur eine spätrömische Welt darstellen, in der die Vandalen eine Rolle spielten. ${ }^{67}$

Ikonographisch fundieren wollte man eine vandalische Tracht weiters mit den so genannten nordafrikanischen Jagdmosaiken, deren bekannteste aus Karthago Bordj-Djedid (heute im British Museum) stammen, die angeblich vandalische Reiter zeigen. Die Datierung der Bordj-Djedid Mosaiken ging immer von den barbarischen Hosen (bracae), der langärmligen Tunika, der Haar- und Barttracht, der Gürtelgarnitur und dem Brandzeichen der dargestellten Pferde aus. Alle diese Elemente sind aber entweder der Jagd und dem Reiten zuzuordnen, oder stehen in einer Nähe zur militärischen Kleidung. ${ }^{68}$ Einer der als chasseur vandale angesprochenen Reiter hat den rechten Arm in scheinbar siegreicher Pose von sich gestreckt, was die Deutung als Vandale zusätzlich zu untermauern schien. Bereits Georges Ville hat gezeigt, dass es sich bei solchen Hosen nicht um ein spezifisch barbarisches Kleidungsstück handeln kann. Schon in der ersten Hälfte des dritten Jahrhunderts kennt man Hosen, Tunika und Mantel als gängige Kleidung bei Jägern wie Militärs. ${ }^{69}$ Auch die Tunika, geschmückt mit einem clavus und Streifen am Ärmel, ist keineswegs ein barbarisches Kennzeichen. Wie die Hosen tauchen diese Verzierungen schon im vorvandalenzeitlichen Afrika und auch sonst nicht selten auf Reichsgebiet auf. Ebenso sind die helmartige Frisur der Reiter und der Bart auf anderen Darstellungen in nicht-barbarischen, militärischen Zusammenhängen nachweisbar. Die Szenerie der Mosaiken und der habitus der Reiter stehen in einer spätantiken Tradition der Darstellung von Jagden von Gutsbesitzern. ${ }^{70}$

Von Rummel spricht von einer „anlassgebundenen zeitgenössischen Kleidung“, bei der es sich nicht um ein „ethnisches Kennzeichen“ handelt. Gestützt wird diese Sichtweise mit einer Verordnung aus dem Codex Theodosianus. Im Jahre 397 wurde von Arcadius und Honorius das Tragen von Stiefeln (tzangae) und Hosen (bracae) in der Stadt Rom verboten. Diese militärische Kleidung (und nur dadurch mit ,barbarisch' verbunden) findet sich im Codex Theodosianus nun explizit für die Stadt Rom verboten: Usum tzangarum adque bracarum intra urbem venerabilem nemini liceat usurpare. Zuwiderhandeln wurde

67 Merrills - Miles, The Vandals (wie Anm. 2) S. 83-87, Zitat: S. 83.

68 Von Rummel, Habitus barbarus (wie Anm. 57) S. 231 - 244; von Rummel, Habitus Vandalorum? (wie Anm. 64) S. 137-140; Ders., Les Vandales ont-ils porté en Afrique un vêtement spécifique? (wie Anm. 54) S. 283-284.

69 Georges VILLE, Le costume dans l'Afrique romaine. Le pantalon, in: Africa 2 (1967-1968) S. $139-148$.

70 Von Rummel, Habitus barbarus (wie Anm. 57) S. 231-245. 
mit Enteignung und Verbannung geahndet. Weiters verboten innerhalb der Mauern Roms war das Tragen langer Haare und von Kleidung aus Pelzen, allesamt barbarisch-militärische Accessoires. Die Vandalenkönige taten nun das schiere Gegenteil und erlaubten oder förderten sogar die genannte Mode. Ähnlich wie Hunerich also gegen die Katholiken die kaiserliche Ketzergesetzgebung angewandt hatte, drehte er offenbar auch die Kleidungsvorschriften um. ${ }^{71}$ Zusammenfassend ließe sich sagen, die neuen Herren Nordafrikas schufen ein Milieu, in dem alle in anderen Provinzen des Reiches benachteiligten Angehörigen des militärischen Standes unter Föderatenrecht bevorzugt oder gleichgestellt wurden. All dies ist römisch, nur erweitert oder in eine andere Richtung gebracht.

In der archäologischen Forschung bestehen zurzeit im Wesentlichen zwei Standpunkte. Der eine, im Freiburger Umfeld Heiko Steuers vertretene, lehnt die Kategorien ,Tracht' und ,ostgermanisch' ab und definiert ein ,vandalisches Grab aufgrund des offensichtlichen hohen sozialen Rangs der Bestatteten und der im nordafrikanischen Umfeld außergewöhnlichen Ausstattung. Voraussetzung für diesen Zugang ist die Annahme einer überregionalen Elitenmode. Somit wäre eine Kleidung, die rang- und funktionsbedingt oder vielleicht als Ausdruck eines Bekenntnisses zu einem politischen Programm verstanden werden sollte und offensichtlich auch am Hof von Karthago getragen wurde, mit der oben besprochenen Stelle bei Victor von Vita beschrieben. ${ }^{72}$ Archäologische wie ikonographische Belege für eine Identifizierbarkeit von Vandalen und Alanen in Nordafrika bestehen demnach nur in expliziten Kontexten, etwa also in Bauinschriften und anderen repräsentativen Elementen und beziehen sich auf das Repräsentationsbedürfnis einer Elite, nicht aber auf eine eingewanderte Bevölkerung, die ihre Trachten, Sitten und Gebräuche mitgebracht hätte. Zusam-

71 Codex Theodosianus, 14, 10, 2-3, edd. Theodor Mommsen - Paul KrüGER - Paul M. Meyer, Hildesheim 22005, S. 345. Vgl. von Rummel, Habitus barbarus (wie Anm. 57) S. 156-166; Howe, Vandalen, Barbaren und Arianer (wie Anm. 9) S. 174 ff. und Anm. 70; Demandt, Die Spätantike (wie Anm 3) S. 339 f., 383; Javier ArCE, Dress control in Late Antiquity: Codex Theodosianus 14.10.1 - 4, in: Kleidung und Repräsentation in Antike und Mittelalter, hg. von Ansgar Кӧв - Peter RıEdel (MittelalterStudien des Instituts zur interdisziplinären Erforschung des Mittelalters und seines Nachwirkens 7) München 2005, S. $33-44$ bezieht die genannten Stellen auf kaiserliche Privilegien betreffend den Kleiderluxus. Vgl. auch die Arbeiten Philipp von Rummel, Ambrosius, Julianus Valens und die ,gotische Kleidung، Eine Schlüsselstelle historisch-archäologischer Interpretation, in: Zwischen Spätantike und Frühmittelalter, hg. von Sebastian BRATHER (Reallexikon der Germanischen Altertumskunde Erg. Bd. 57) Berlin - New York 2008, S. 45-64; Ders., Gotisch, barbarisch oder römisch? Methodologische Überlegungen zur ethnischen Interpretation von Kleidung, in: Archäologie der Identität, hg. von Walter PoHL - Mathias MeHofer (Österreichische Akademie der Wissenschaften. Denkschriften der phil.-hist. Klasse 386. Forschungen zur Geschichte des Mittelalters 16) Wien 2010, S. 51 - 78.

72 Von Rummel, Habitus barbarus (wie Anm. 57) S. 376-406. 
menfassend könnte man formulieren, dass es eine ,vandalische Archäologie nicht gibt. Dagegen wurde vorgeschlagen, von einer, vandalenzeitlichen Archäologie‘ zu sprechen, da dies wesentlich mehr Material impliziert. ${ }^{73}$

Die vor allem von Volker Bierbrauer und seinen Schülern in München vertretene Interpretation der archäologischen Situation im spätantiken Nordafrika hält, wenn auch zurückhaltender als noch vor wenigen Jahren, an Trachtelementen, hier vor allem Fibeln, und der Möglichkeit einer so vornehmbaren Zuordnung von Grabinventaren zu einer vandalischen Ethnie fest. Denkerische Voraussetzungen für eine solche Interpretation bleiben eine personengebundene Migration als Kontext für Schmuck, Gewand, Fibeln und Bestattungssituationen wie die Annahme einer Traditionsbindung an Kulturgruppen außerhalb der Reichsgrenzen. Auch die vieldiskutierte Stelle bei Victor von Vita wird so gelesen: „Ohne gemischt zu argumentieren, darf man diesen habitus barbarus auf die weibliche Peplostracht beziehen. ${ }^{\text {c74 }}$

Insgesamt bleibt festzustellen, dass entgegen der doch im Ganzen gut funktionierenden politischen Ordnung in den römischen afrikanischen Provinzen unter Leitung einer neuen, militärischen Elite unsere Quellen, mit Ausnahme der archäologischen, Gegensätzliches betonen. Victor von Vita hatte als Angehöriger des katholischen Klerus ein massives Interesse, ein negatives Bild der Verhältnisse zu zeichnen. Wie insgesamt die alten, etablierten Eliten mit den ihnen zur Verfügung stehenden Mitteln literarischer Produktion die neuen Militäreliten als ihre Konkurrenten negativ zeichneten, ist dies auch für die katholischen Quellen der Fall. Mehr als ein Jahrhundert gemeinsamer politischer, sozialer und ökonomischer Organisation hatte aber in Nordafrika neue gesellschaftliche Realitäten und Lösungen entstehen lassen, auch wenn es verschiedene scharfe Abgrenzungsversuche gegeben hat wie etwa die Warnung Victors von Vita an jene Römer, die die Barbaren mögen und manchmal preisen, deren wahre, grausame und zerstörerische Natur nur ja nicht zu vergessen. ${ }^{75}$ Victor dürfte nicht nur Salvianus' Ausführungen angegriffen haben, denen zufolge die Vandalen die keuschesten, tugendhaftesten und reinsten aller Barbaren seien und Gott ihnen deshalb in Spanien Erfolg gegönnt hätte, um die sündhaften Spanier zu strafen und die gerechten Barbaren zu belohnen. Auch die Reichspolitik und jene Römer, die mit oder für die Vandalen arbeiteten, standen im Visier des katholischen Apologeten. ${ }^{76}$

73 Philipp von Rummel, Zum Stand der afrikanischen Vandalenforschung, in: Antiquité Tardive 11 (2003) S. $13-19$, hier S. 17.

74 Bierbrauer, Wandalen $\$ 2$ (wie Anm. 56) S. 215.

75 Vict. Vit. (wie Anm. 4) 3, 69.

76 Salvianus von Marseille, De Gubernatione Dei (wie Anm. 18) 7, 7, 26-28; vgl. Castritius, Vandalen (wie Anm. 18) S. 10-11. 
